\title{
Functional Analysis of Seven Genes Linked to Body Mass Index and Adiposity by Genome-Wide Association Studies: A Review
}

\author{
John R. Speakman \\ Key State Laboratory of Molecular Developmental Biology, Institute of Genetics and Developmental Biology, \\ Chinese Academy of Sciences, Beijing, PR China; Institute of Biological and Environmental Sciences, \\ University of Aberdeen, Aberdeen, UK
}

\section{Key Words}

Body mass index - Adiposity - Genome-wide association

studies · FTO - NEGR1 - TMEM18 - ETV5 - FLJ35779.

LINGO2 $\cdot S H 2 B 1 \cdot G I P R$

\begin{abstract}
Genome-wide association studies (GWAS) have identified a total of about 40 single nucleotide polymorphisms (SNPs) that show significant linkage to body mass index, a widely utilised surrogate measure of adiposity. However, only 8 of these associations have been confirmed by follow-up GWAS using more sophisticated measures of adiposity (computed tomography). Among these 8 , there is a SNP close to the gene FTO which has been the subject of considerable work to diagnose its function. The remaining 7 SNPs are adjacent to, or within, the genes NEGR1, TMEM18, ETV5, FLJ35779, LINGO2, SH2B1 and GIPR, most of which are less well studied than FTO, particularly in the context of obesity. This article reviews the available data on the functions of these genes, including information gleaned from studies in humans and animal models. At present, we have virtually no information on the putative mechanism associating the genes FLJ35779 and $\mathrm{LINGO2}$ to obesity. All of these genes are expressed in the brain, and for 2 of them (SH2B1 and GIPR), a direct link to
\end{abstract}

the appetite regulation system is known. SH2B1 is an enhancer of intracellular signalling in the JAK-STAT pathway, and GIPR is the receptor for an appetite-linked hormone (GIP) produced by the alimentary tract. NEGR1, ETV5 and $S H 2 B 1$ all have suggested roles in neurite outgrowth, and hence SNPs adjacent to these genes may affect development of the energy balance circuitry. Although the genes have central patterns of gene expression, implying a central neuronal connection to energy balance, for at least 4 of them (NEGR1, TMEM18, SH2B1 and GIPR), there are also significant peripheral functions related to adipose tissue biology. These functions may contribute to their effects on the obese phenotype.

(c) 2013 S. Karger AG, Basel

\section{Introduction}

The human genome project, and the subsequent development of tools allowing identification of genome-wide polymorphic variation at key variable nucleotides, has opened up a new era in the genetic analysis of complex traits [21]. This has included genome-wide association studies (GWAS) of several important disease states, such as diabetes [19, 108, 110, 115], hypertension [2, 57, 83],

\section{KARGER}

E-Mail karger@karger.com

www.karger.com/hhe
C 2013 S. Karger AG, Basel

0001-5652/13/0754-0057\$38.00/0
John R. Speakman

Institute of Biological and Environmental Sciences

University of Aberdeen

Aberdeen AB24 2TZ (UK)

E-Mail J.speakman@ abdn.ac.uk 
heart disease [72], cancer [25, 47, 112, 118], Parkinson's disease [106, 113], Alzheimer's disease [40] and chronic obstructive pulmonary disease [92]. In addition, GWAS have investigated traits that do not have disease associations such as height $[135,143]$ and age at menarche [90]. In the last 7 years, there have been at least 5 major GWAS studies, each analysing $>50,000$ individuals, that have aimed to associate the variation in single nucleotide polymorphisms (SNPs) to variation in body mass index (BMI). These include associations established across approximately 450,000 Caucasian subjects and around 150,000 East Asians [86, 89, 116, 136, 137]. BMI is defined as body mass (in $\mathrm{kg}$ ), divided by height (in $\mathrm{m}$ ) squared, and is a widely used surrogate for adiposity, although its limitations in this respect are well known [91, 100]. Nevertheless, BMI is an easily measured phenotype that lends itself to the large sample sizes necessary to achieve sufficient power in GWAS, and it is widely used in epidemiological studies and surveys of obesity prevalence.

Many of the target SNPs that have been identified have been replicated across different populations, lending support to the idea that they are functionally associated with obesity. However, GWAS based on more sophisticated analyses of body adiposity, using computed tomography (CT), only confirmed a link to either visceral or subcutaneous adiposity at 8 of these loci [29]. The nearest genes to these 8 SNPs are NEGR1, TMEM18, ETV5, FLJ35779, LINGO2, SH2B1, FTO and GIPR. We can be very confident that these 8 identified associations reflect some underlying biological association between the genetics and the obese state - presumably acting via an impact on energy balance [37]. Of these genes, the most well known and characterised is FTO, although despite this attention there still remains considerable uncertainty over its function and mechanism [e.g. 62, 70, 122]. The aim of this article is to review what we know about the functions of the other 7 less well-studied genes located nearest to the identified SNPs, and to speculate where possible what the functional nature of their linkage to obesity might be. By making this selection, I do not mean to imply that the other SNPs identified by GWAS are not associated to adiposity. There is a potential bias in the CT GWAS study by Fox et al. [29] because they only included individuals of European ancestry, and they only examined 2 fat stores. Moreover, the selection of SNPs here was based only on the overall analysis of pooled sexes, and it should be noted that some SNPs are known to exert sex-specific effects (e.g. rs1659258 near to the gene THNSL2). Finally, the sample size of the CT study [29] $(\mathrm{n}=10,557)$ was necessarily much lower than in the other studies, because of the sophisticated and expensive nature of the phenotyping employed. This reduces the power to detect significant associations. Thus, only the SNPs with the greatest effect passed the hurdle of being significant in their study.

The evidence relating to each SNP will be reviewed in the sequence they appear in the human genome, starting at chromosome 1 and ending at chromosome 19. To date, no SNPs significantly associated to obesity have been identified on chromosomes $20-23$ or the X/Y chromosomes in GWAS studies.

\begin{tabular}{|ll|}
\hline SNP & rs2815752 \\
\hline Other significant nearby SNPs & rs3101366, rs2568598 \\
Chromosome & $1 \mathrm{p} 31.1$ \\
BMI link identified in & {$[116,137]$} \\
Location of SNP & Intergenic \\
At risk allele & A \\
Nearest gene & Neuronal growth regulator 1 \\
& (NEGR1) \\
Synonyms & IgLON4, Kilon, neurotractin \\
Entrez gene reference & 257194 \\
Ensembl gene reference & ENSG00000172260 \\
\hline
\end{tabular}

In 1999, a novel immunoglobulin superfamily member was identified that had three $\mathrm{C} 2$ domains and several potential sites for $\mathrm{N}$-glycosylation [33]. Since the protein showed high sequence similarity to IgLON family members, it was called Kilon (kindred of IgLON). Western blotting showed that the expression of Kilon was brain specific (notably in the hippocampus). It was already detectable at the E16 stage, and its level slowly increased during development and was maintained into adulthood [33]. At the same time, a second group discovered the same protein in the chicken using a different strategy. They called the gene neurotractin [65]. They discovered that recombinant neurotractin promoted neurite outgrowth of chicken telencephalic neurons, implicating it as a key player in the regulation of neurite growth. The homology between Kilon and neurotractin was recognised by Bauer et al. [11], and they were subsequently renamed neuronal growth regulator 1 (NEGR1). However, many papers continue to use the name Kilon, particularly in the brain development field. Since some papers use NEGR1 and others use Kilon, I will refer to it hereafter as Kilon/ NEGR1.

Kilon/NEGR1 is 1 of 4 members of the IgLON family, the others being limbic-associated membrane protein (LAMP), opioid-binding cell adhesion molecule (OBCAM) and neurotrimin (Ntm) (also called CEPU-1).
58

Hum Hered 2013;75:57-79 DOI: $10.1159 / 000353585$
Speakman 
The function of Kilon/NEGR1 has been disputed since its initial description, with some suggesting it is primarily involved in cell-cell adhesion [71], while others maintain a function in neurite outgrowth and synaptogenesis [75, 109]. In situ hybridisation has been used to analyse the distribution of Kilon/NEGR1 in the developing and adult rat hippocampus, compared to the distribution of LAMP [11]. Gene expression of both genes was not responsive to hippocampal deafferentation and seizure, suggesting they do not play a role in neurite outgrowth.

Contrasting these studies, lesions in the entorhinal cortex did result in induction of Kilon/NEGR1 expression in reactive astrocytes where regenerative axon sprouting occurs [109]. In addition, it was shown that Kilon/NEGR1 attracted hippocampal axons and that astroglial Kilon/NEGR1 promoted neurite outgrowth [109]. These results suggested a function for Kilon/NEGR1 as a trans-neural growth factor for outgrowing axons, following hippocampal denervation. Since Kilon/NEGR1 was also found to be upregulated during brain development, and was particularly expressed on neurites of primary hippocampal neurons, a role in axon growth during hippocampal development is also implied. None of these suggested functions in the hippocampus, however, give a hint to its role in obesity.

Miyata et al. [75] suggested that there could be a role for Kilon/NEGR1 in synaptogenesis, since immunohistochemistry demonstrated co-localisation of Kilon/NEGR1 with vesicle-associated membrane protein 2 , a synaptic marker protein. This suggestion of a role for Kilon/ NEGR1 in synaptogenesis was supported by observations that in cultured neurons, Kilon/NEGR1 localised chiefly at axons and presynaptic terminals at the early culture stage [42]. In later stages of culture, however, it was observed mostly at the dendritic postsynaptic spines of mature neurons. Overexpression of Kilon/NEGR1 also had variable effects depending on the culture stage. Early in culture, it decreased the number of dendritic synapses, while in late culture, it increased them [41, 42].

The primary focus of work on Kilon/NEGR1 has been in the hippocampus, a brain area not traditionally associated with studies of energy balance. However, it is also found in other brain regions. Using western blotting, the protein was found abundantly in the olfactory bulb, cerebral cortex, diencephalon, hippocampus and cerebellum, with low expression levels in the medulla oblongata and spinal cord [74]. Interestingly, in the context of regulation of energy balance, high levels of Kilon/NEGR1 have also been observed in the arginine-vasopressin (AVP) and oxytocin (OXT) magnocellular neurons of the rat hypo-

Functional Analysis of 7 Genes Linked to BMI and Adiposity thalamus [75]. Kilon/NEGR1 immunoreactivity was localised mainly in the dendrites of AVP-secreting neurons (and also occasionally OXT-secreting neurons) [75]. The AVP and OXT magnocellular neurons in these nuclei display reversible structural plasticity under different conditions. Localised expression of Kilon/NEGR1 (and OBCAM), particularly in dendrites, might suggest that these molecules play an important role in rearranging dendritic connectivity of these neurons. Using an in vitro assay with cells derived from mice that had the Kilon/ NEGR1 gene knocked out, it has been shown that Kilon/ NEGR1 plays a key role in both cell-cell adhesion and neurite outgrowth in hypothalamic neurons [56]. AVP and OXT have both been implicated in the regulation of energy balance. Systemic leptin, for example, increased the electrical activity of OXT neurons in the supraoptic nucleus [124], and it restored gene expression (mRNA) levels of both OXT and AVP in fasted mice to non-fasted levels [121]. Peripherally administered OXT reduced food intake and reversed diet-induced obesity in both rats $[9,22]$ and mice $[63]$. OXT receptor-deficient mice develop obesity [117]. Arginine-vasopressin, on the other hand, seems to interact with Neuropeptide Y in the regulation of food intake [6]. Interestingly, the AVP- and OXT-expressing neurons in the supraoptic nucleus and paraventricular nucleus also express nesfatin-1, an anorexigenic molecule first identified in 2006 [84]. This points to a potential additional molecular route by which Kilon/NEGR1 may exert its effects on food intake via modulation of nesfatin-1. High levels of Kilon/NEGR1 have been reported in other nuclei of the hypothalamus [110], and nutritional state affected the gene expression levels of Kilon/NEGR1 in the ventromedial and arcuate nuclei and the substantia nigra/ventral tegmental area (VTA). This suggests a potential direct link to food intake and energy balance regulation [15]. Whether these effects are dependent on AVP, OXT or nesfatin-1 modulation remains unknown, since the changes are located in different hypothalamic nuclei.

Outside of the brain, Kilon/NEGR1 is highly expressed in several peripheral tissues (fig. 1). Relative to the brain, expression in white adipose tissue was 3-fold higher, while it was 5 -fold higher in smooth muscle than in the brain and 6.5-fold higher in the pituitary gland than the brain (fig. 1) [13]. In contrast, gene expression was almost absent in the liver [13]. Walley et al. [129] explored differential gene expression in subcutaneous adipose tissue collected from 154 sibling pairs of subjects who were discordant for obesity status. Genome-wide transcript expression was measured using microarrays, and it was 


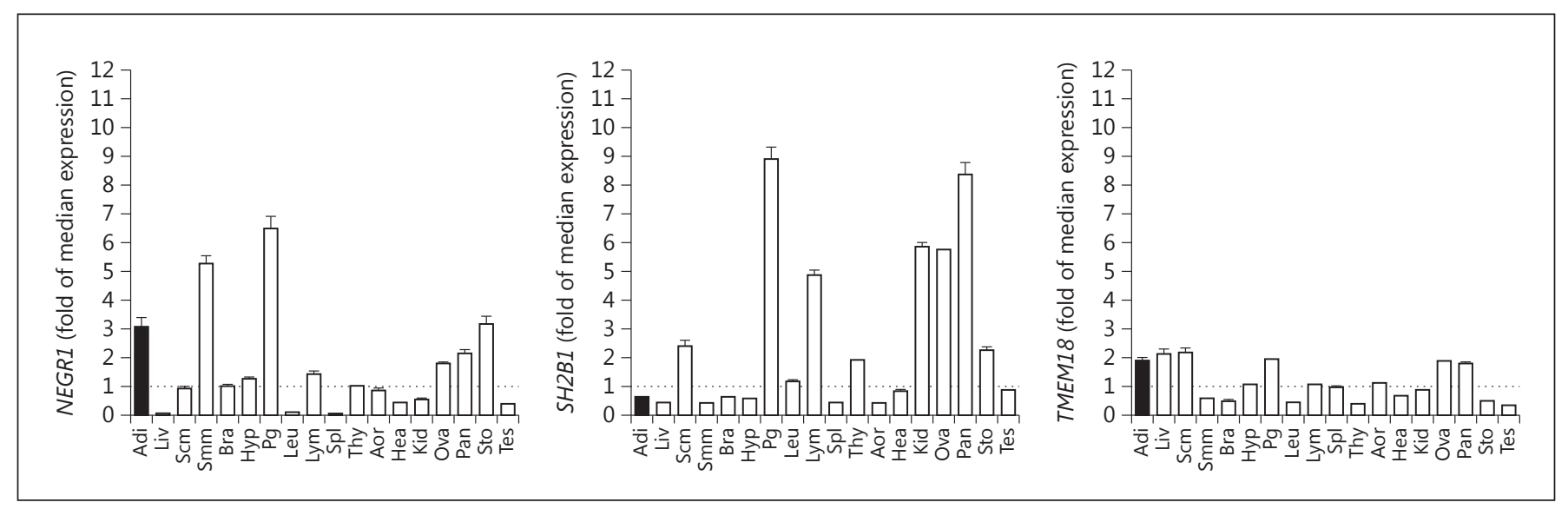

Fig. 1. Gene expression levels of 3 putative obesity genes (NEGR1, TMEM18 and SH2B1) in human tissues. Adi = Adipose tissue; Liv $=$ liver $; \mathrm{Scm}=$ skeletal muscle $; \mathrm{Smm}=$ smooth muscle; $\mathrm{Bra}=$ brain; Hyp = hypothalamus; Pg = pituitary; Leu = leukocytes; Lym = lymph node; Spl = spleen; Thy = thymus; Aor = aorta;
Hea = heart Kid = kidney; Ova = ovary; Pan = pancreas; Sto = stomach; Tes = testis. All 3 genes showed a wide tissue distribution despite previous suggestions that they are centrally acting [from 13]. found that almost one third of the transcripts were differentially expressed between lean and obese siblings. Cellular adhesion molecules contained the largest number of differentially expressed genes. It was noted that there was a subset of differentially regulated genes in a network, with Kilon/NEGR1 as a central hub. This suggested that, in addition to its central role as a factor influencing neuron architecture, Kilon/NEGR1 may have additional functions in adipose tissue. The expression of Kilon/NEGR1 in adipose tissue has been suggested to be linked to its role in promoting adipogenesis. In cell culture of human adipocytes, there was a 2-fold upregulation of Kilon/NEGR1 during adipogenesis [13] relative to quiescent adipocytes. A causal linkage was implied, as adipogenesis was inhibited by siRNA knockdown of Kilon/ NEGR1. Insulin and IGF-1 both significantly reduced the expression of Kilon/NEGR1 in adipocytes, but it was significantly upregulated by treatment with dexamethasone. Isoprenaline had no significant effect [13].

Lee et al. [56] generated a constitutive Kilon/NEGR1deficient mouse. Mice with the Kilon/NEGR1 gene ablated weaned (day 20) about 25\% lighter than wild-type or heterozygous mice. Over the next 10 weeks, there was a clear retardation of growth, with the knockout (KO) mice being about $10 \%$ lighter at week 10 , although this difference narrowed over the next 8 weeks so that by week 18 , they were only $6 \%$ lighter. Interestingly, the difference in body composition between the wild-type and $\mathrm{KO}$ mice was solely due to the difference in lean mass rather than a difference in fat mass (fig. 2) [56]. Because the mice had equal body fat contents but different lean masses, the percentage of body fatness was elevated in the mice with the loss of the Kilon/NEGR1 gene. This pattern shows a clear difference to the situation in humans, where carriers of the at risk 'A' form of the SNP at rs2815752 (upstream of Kilon/NEGR1) have elevated levels of both subcutaneous and visceral fat stores, as determined by CT [29]. This latter observation for a role in regulating the levels of fat stores in humans is supported by the effects of Kilon/ NEGR1 in human adipogenesis [13], where it was shown that Kilon/NEGR1 was 2-fold upregulated during adipogenesis, and siRNA knockdown of Kilon/NEGR1 inhibited adipogenesis [13].

The metabolic rate of the Kilon/NEGR1 KO mouse was lower than that of wild-type mice, but normalising for lean body mass completely removed this effect, implying no impact of the gene on energy expenditure [56]. Although division by lean mass was perhaps not the best way to normalise such data $[7,119]$, the fact that it removed the apparent impact of the gene on energy expenditure is striking (fig. 3). There were also significant effects on food intake and physical activity levels, both of which were lower in the $\mathrm{KO}$ mice. However, no normalisation with respect to body or lean mass was performed for these variables. In humans, a study of 1,700 Dutch females found there was an association between Kilon/NEGR1 genotype and macronutrient intake [12], pointing to a centrally mediated impact on intake, rather than expenditure.
Speakman 

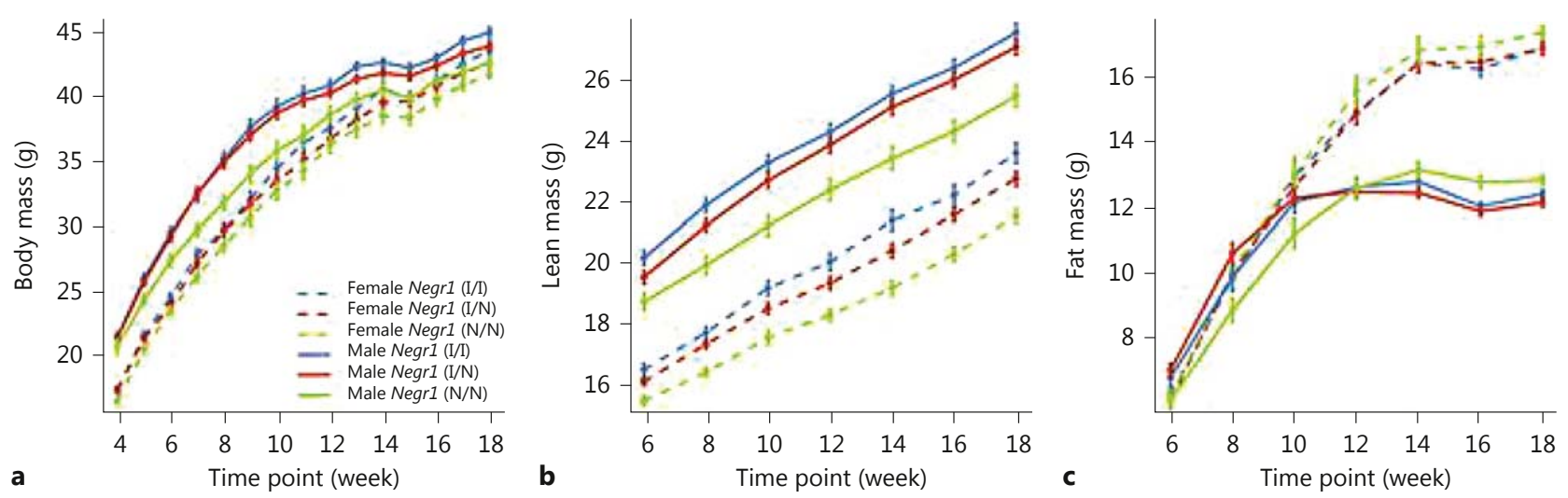

Fig. 2. Body weight (a), lean mass (b) and fat mass (c) gains over time in male and female mice that are wild type $(\mathrm{I} / \mathrm{I})$, heterozygous $(\mathrm{I} / \mathrm{N})$ or homozygous null $(\mathrm{N} / \mathrm{N})$ for the gene NEGR1. The growth curves show an effect of the gene absence on total body weight in both sexes, but this stems mostly from an impact on lean tissue mass rather than on fat mass [from 56].

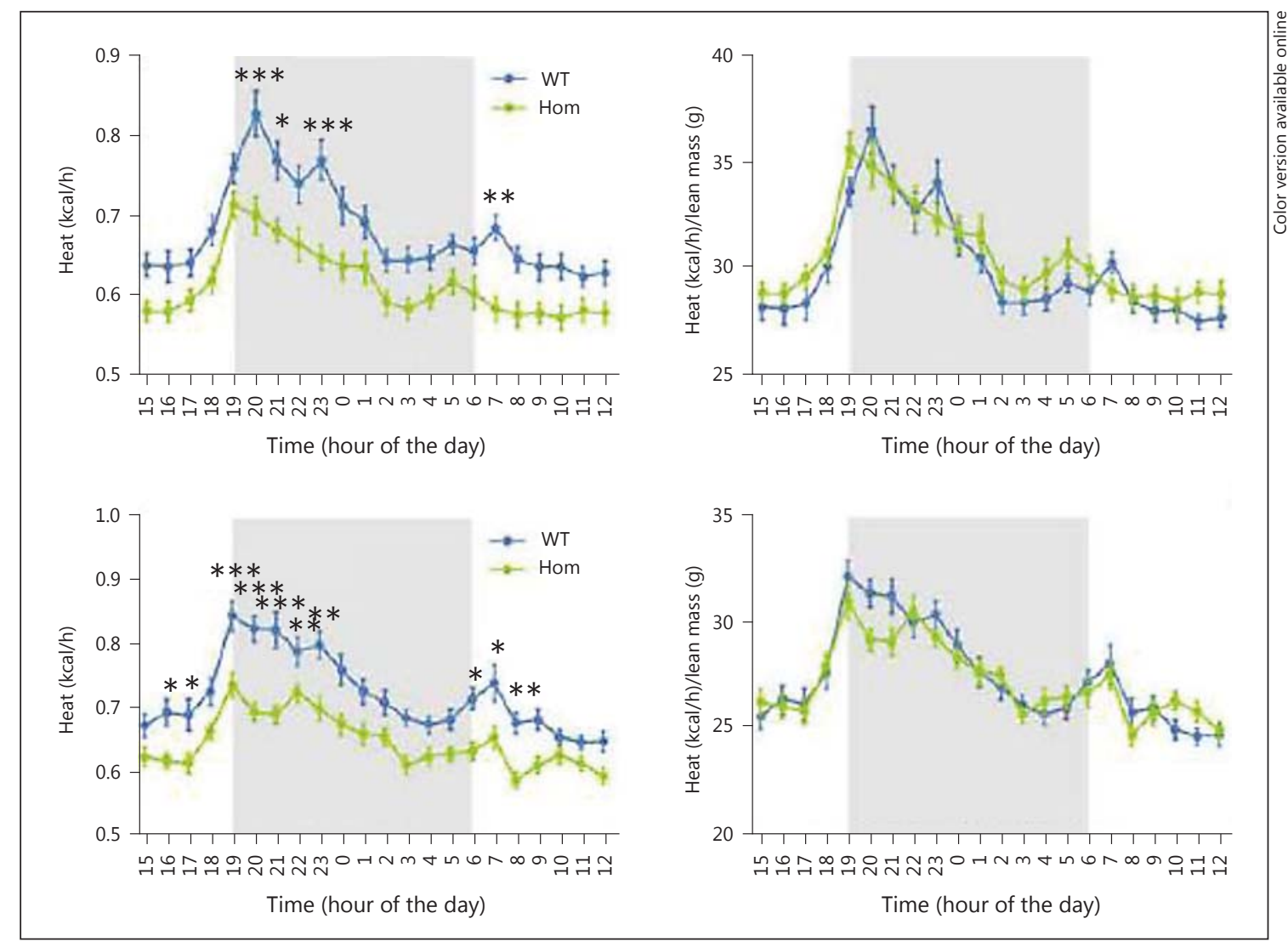

Fig. 3. Differences in energy expenditure between homozygous NEGR1-/- mice and wild-type mice measured over $24 \mathrm{~h}$. Left panels show raw data (male top, female bottom) and right panels show the same data normalised by dividing by lean mass [from 56]. Normalisation removed the impact of the gene KO in both sexes, indicating that the differences in energy expenditure at the whole-animal level were entirely due to the impact of the gene on lean tissue levels. WT $=$ Wild type; Hom $=$ homozygous NEGR1-/- mice. ${ }^{*} \mathrm{p}<0.05 ;{ }^{* *} \mathrm{p}<0.01 ;{ }^{* * *} \mathrm{p}<0.001$. 
Fig. 4. Diagram summarising the effects of

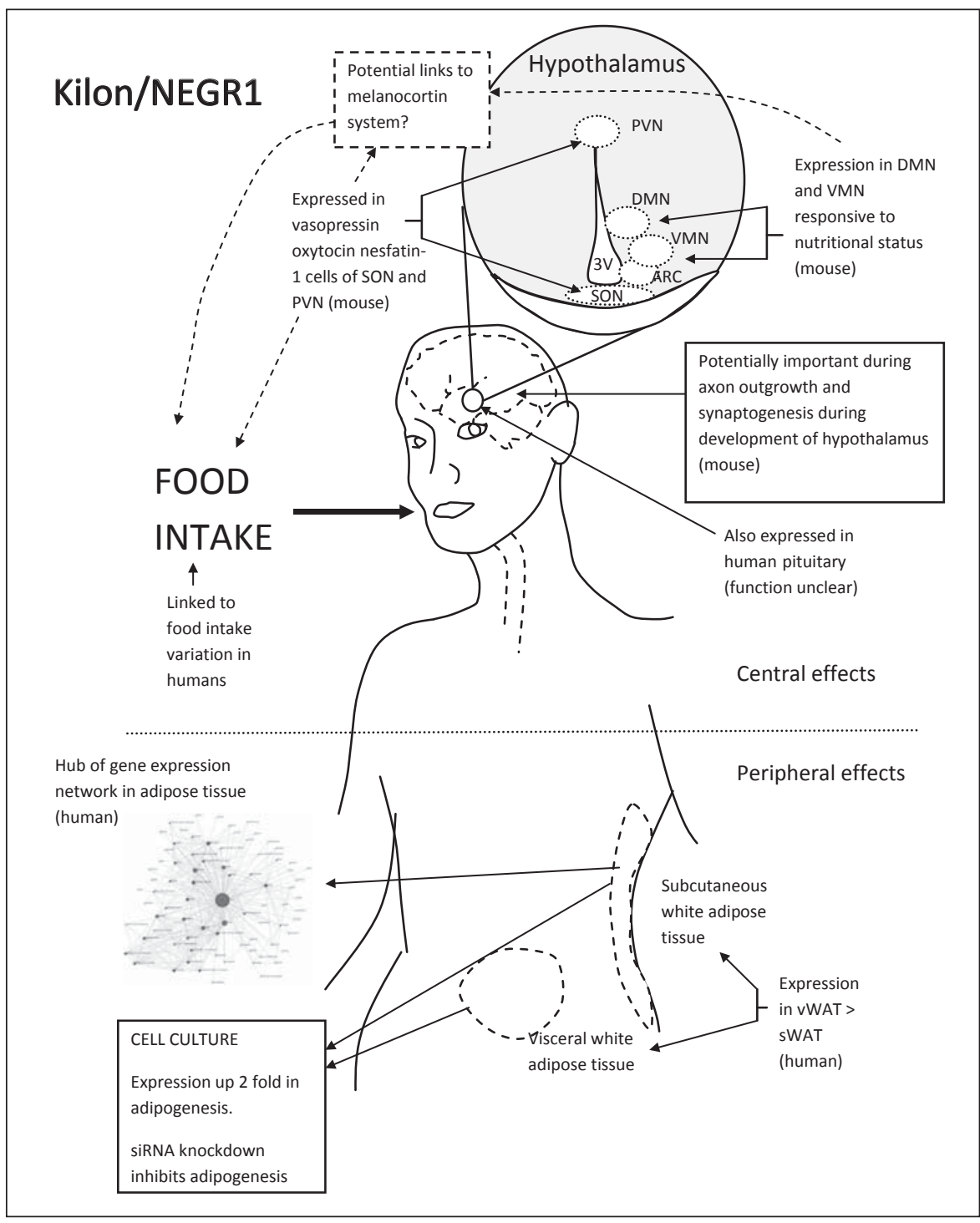
NEGR1 in relation to obesity.

The genetic variants upstream of Kilon/NEGR1 that are linked to BMI are also linked to insulin sensitivity (independent of their effects on BMI) and, hence, may partially mediate the link between obesity and diabetes [22]. In this context, given the different importance of subcutaneous and visceral adipose tissue for insulin resistance and type 2 diabetes risk, it is interesting that Kilon/ NEGR1 gene expression was significantly lower in subcutaneous compared to visceral white adipose tissue [13].

In summary, Kilon/NEGR1 is a cell surface protein found extensively in the brain, which appears to be involved centrally in synaptogenesis, neurite outgrowth and cell-cell recognition/adhesion. Localised expression of Kilon/NEGR1, particularly in dendrites, suggests it might play an important role in rearranging dendritic connectivity. It therefore probably plays a key role in the development and plasticity of the hippocampus and hypothalamus. The responsivity of gene expression for Kilon/NEGR1 in the hypothalamus to nutritional status indicates a potential role in modulating energy balance, potentially linked to AVP, OXT and nesfatin-1 signalling. This may include effects on dendritic connectivity of neurons containing AVP and OXT receptors. This central role is supported by an association between the genetic polymorphisms upstream of Kilon/NEGR1 and food intake in humans. There is, however, a conflict in the data relating to its function in mice and humans. Mice that were null for the gene had a greater percentage of body 
fatness, but this was because of an impact on lean tissue mass, not on fat tissue mass. In contrast, CT studies in humans pointed to a direct impact of the GWAS-identified SNP on fat content. Moreover, there is a suggestion that the gene may be involved directly in adipogenesis in humans. Wider and higher gene expression levels in smooth muscle and the pituitary may underpin other unknown functions related to energy balance. Future studies would benefit significantly from the creation of conditional $\mathrm{KO}$ mice, allowing the central and peripheral functions of the gene to be dissected. Moreover, the interactions between Kilon/NEGR1 and both OXT and AVP status could be profitably explored by examining the changes in gene expression of Kilon/NEGR1 in response to peripheral infusions of OXT and compounds that affect the AVP signalling such as Apelin $[82,107]$ and nesfatin-1 $[53,84,114]$. Links of Kilon/NEGR1 to nesfatin-1 status may be particularly revealing. The relationships between Kilon/NEGR1 and obesity are illustrated in a summary diagram (fig. 4).

\begin{tabular}{|ll|}
\hline SNP & rs2867125 \\
\hline Other significant nearby SNPs & rs2867125, rs4854344, \\
& rs7561317 \\
Chromosome & $2 \mathrm{p} 25.3$ \\
BMI link identified in & {$[116]$} \\
Location & Intergenic \\
At risk allele & $\mathrm{C}$ \\
Nearest gene & Trans-membrane protein 18 \\
& (TMEM18) \\
Entrez gene reference & 129787 \\
Ensembl gene reference & ENSG00000151353 \\
\hline
\end{tabular}

TMEM18 is a small 140 amino acid protein $(17 \mathrm{kDa})$ that is predicted to consist mostly of $\alpha$ helices and has 3 transmembrane domains. Phylogenetic analysis has revealed that the gene has an ancient origin, being found in plants and most other eukaryotic organisms. It is remarkably well conserved across this 1,500 million year evolutionary history [3]. Surprisingly, it has no clear homologs in either yeast or Caenorhabditis elegans. It has a wide distribution of tissue gene expression in both rat and mouse (fig. 5) [3]. In the rat, outside the brain, the highest expression levels were found in skeletal muscle, heart, kidney and the reproductive organs (uterus or testicles). In the mouse, a narrower range of peripheral tissues have been screened, and the highest expression was in the kidney and lung, with relatively low levels in the heart. In human tissues, a similar wide distribution of expression has been found, with maximal levels in adipose tissue, liver and skeletal muscle [13]. Expression was lower in subcutaneous, compared to visceral adipose tissue, and lower in adipose tissue from obese relative to lean subjects [13]. In the brain, there is a widespread distribution, with particularly high expression in the rat in SL7, SL8, brainstem, cerebellum and eye. In the mouse, the highest brain expression occurred in the hypothalamus, thalamus and substantia nigra [3]. These broad patterns of expression do not support the early suggestion that expression is particularly dominant in the hypothalamus [137]. Across 5 regions of the mouse brain (cortex, amygdala, hypothalamus, thalamus and hippocampus), TMEM18 was found in $73 \%$ of neurons, and $64 \%$ of non-neuronal cell types, with no clear differences between brain regions [3].

Early studies suggested an association between the TMEM18 protein and the nuclear membrane, rather than the cell surface $[3,52]$. Two groups have used protein modelling software to predict the structure of the protein, and both predict 3 transmembrane $\alpha$ helices $[3,42]$. Both also noted that the $\mathrm{C}$ terminus of the protein has an array of large hydrophilic amino acids, which causes that end to extend out from the membrane. Jurvansuu and Goldman [51] indicated that the $\mathrm{C}$ terminus extends into the nucleus, rather than out into the cytoplasm, but Almèn et al. [3] suggested the reverse. The protruding part of the $C$ terminus, with several positive amino acids, is a good candidate to bind DNA, particularly if it projects into the nucleus. By incubating together chromosomal DNA linked to cellulose, and protein extracts from TMEM18overexpressing cells, proteins bound to the DNA were eluted with a high salt concentration, and these included TMEM18 [51]. However, mutated TMEM18 lacking the 13 C-terminal amino acids did not bind to either single or double-stranded DNA, showing that the C terminus is required for TMEM 18 to bind to DNA. This supports the model where the $\mathrm{C}$ terminus projects to the nucleus rather than into the cytoplasm [51]. The TMEM18 DNAbinding domain is only one a helix, and so the DNA target sequence for binding is expected to be quite short. TMEM 18 binds to different 3 nucleotide words with different affinity (fig. 6), but there was no clear preference among 4 nucleotide words [51]. GCT and CTG were the most preferred binding sequences. Bound TMEM18 represses DNA transcription, possibly by simply physically excluding transcription factors from promoter regions. Clearly, binding to nucleotide trimers would be very nonspecific, but the molecule readily dimerises providing a mechanism to increase specificity, whereby adjacent Cterminal ends of the protein would bind to repeated GCT elements, increasing the length of the target sequence 


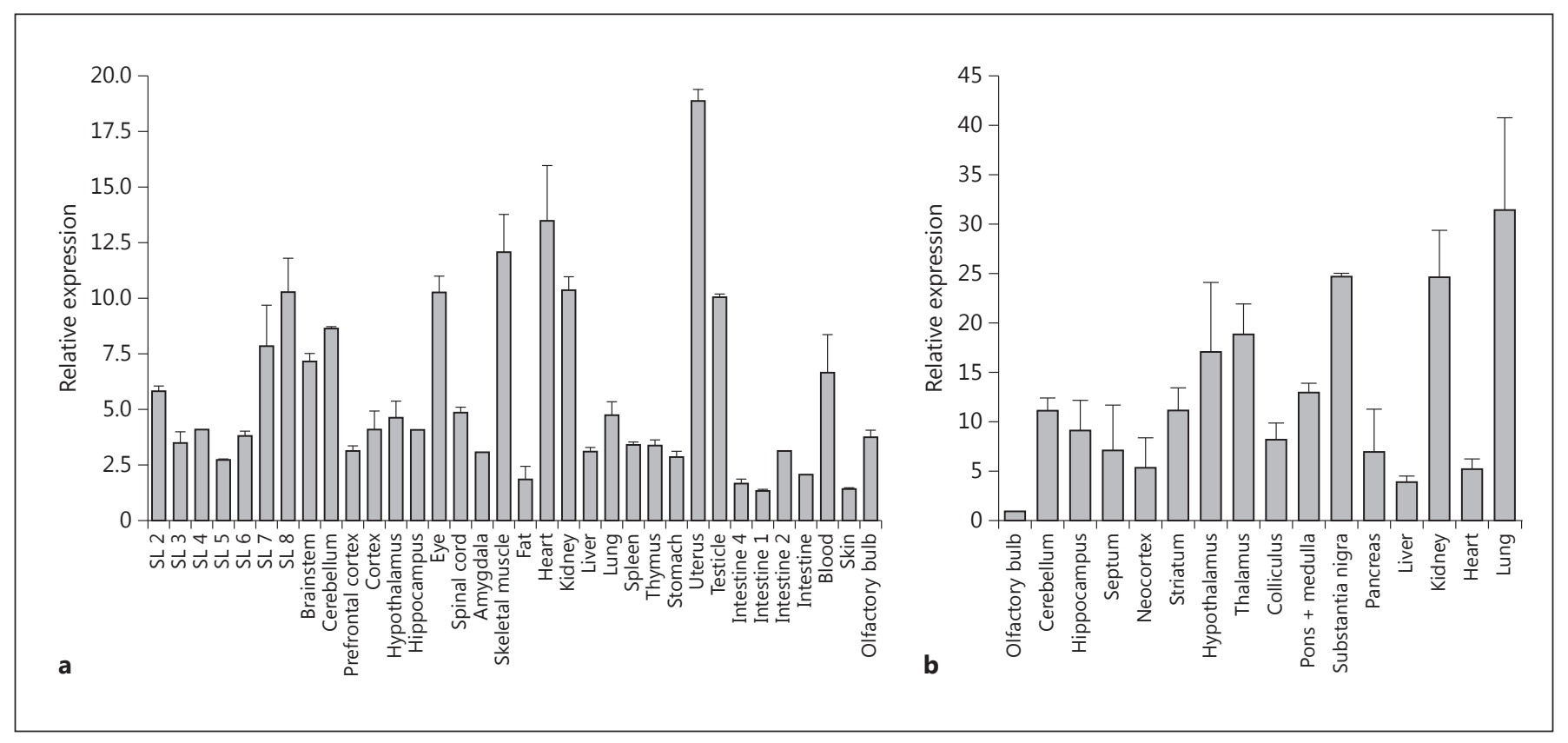

Fig. 5. Tissue-specific gene expression profiles for the gene TMEM18 in the rat (a) and mouse (b), relative to the lowest expressed tissue. The gene is expressed widely both within and outside the brain. See also figure 1 for tissue distribution of gene expression in humans [from 3]. SL 2-8 designate sequential coronal sections of the rat brain.

[51]. To date, however, specific DNA targets have not been identified, apart from the suggestion that it may suppress transcription in the transcriptional regulator Yin-Yang1 [51].

It therefore appears that TMEM18 sits on the nuclear membrane with a DNA-binding domain extending into the nucleus, which binds to specific binding sites, thereby regulating transcription. Given this model, an obvious potential mechanism by which TMEM18 may be linked to energy balance is via transcriptional repression of genes linked to food intake or energy expenditure. This viewpoint, however, is not supported by observations that there were no changes in the gene expression of TMEM18 in either the hypothalamus or brainstem of mice in relation to food deprivation (16 or $24 \mathrm{~h}$ ), or to short $(48 \mathrm{~h}$ ) or long-term ( 3 weeks) exposure to a palatable dietary supplement: sucrose water or intralipid [3]. This lack of change in reported gene expression might be because TMEM18 is so widely expressed that TMEM18 levels in subpopulations of neurons are significantly altered, yet overall expression remains unchanged [3]. Another possibility, however, given the conserved glycosylation and phosphorylation sites, is that TMEM18 is mostly regulated posttranslationally rather than transcriptionally. Contrasting with the data for mice, it was observed that TMEM18 was downregulated in the hypothalamus of Long-Evans rats when fed a high-fat diet for 6 weeks [35]. This could be a species- or a diet-related difference, although as with the mice, starvation for $24 \mathrm{~h}$ did not affect expression levels of TMEM18 in the hypothalamus of the rats.

A further possibility is that given the distribution of TMEM18 among peripheral tissues, the relation of this gene to obesity is not via any centrally mediated action. In this sense, TMEM18 may be similar to Kilon/NEGR1, where the initial emphasis was on its central role, but has turned more recently to its potential role at the hub of a network in adipose tissue related to adipogenesis (discussed above). Supporting this alternative view, gene expression of TMEM 18 in mice was reduced by $80 \%$ in adipose tissue during high-fat feeding [145], but brain levels were unaffected, as was observed by Almèn et al. [3] TMEM18 expression was approximately doubled during adipocyte differentiation, in human adipocyte culture, and knockdown of the gene by siRNA approximately halved the rate of adipogenesis [13]. Insulin, IGF-1 and dexamethasone all significantly reduced gene expression of TMEM18 in adipose tissue, but there was no significant effect of isoprenaline [13]. In the periphery, in response to 6 weeks' feeding on a high-fat diet, TMEM18 expres- 


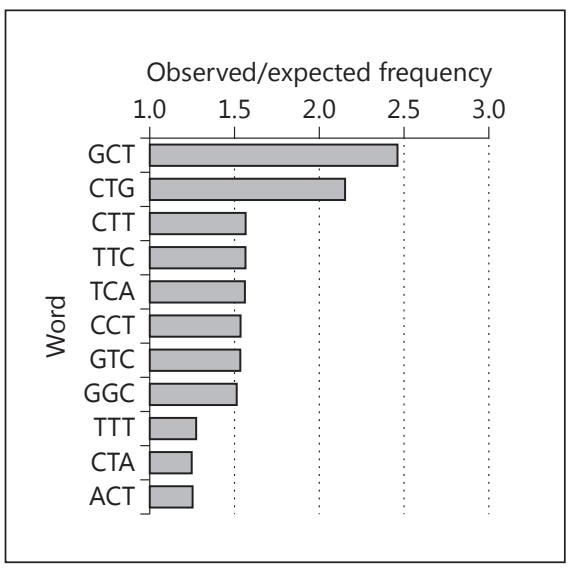

Fig. 6. Binding affinity of TMEM18 for different nucleotide triplets (words) on double-stranded DNA [from 51]. TMEM18 shows differential affinity for different 3-letter words but shows no differential affinity for 4-letter words. The differential affinity for DNAbinding sites may provide a mechanism by which TMEM18 acts as a transcriptional inhibitor.

sion was downregulated in the liver and soleus muscle of rats, but adipose tissue levels were unaffected [35].

Unsurprisingly, given its widespread distribution, TMEM18 has been implicated in several other disease states aside from obesity, notably in relation to cancer. Indeed, the gene was first identified as a terminal oligopyrimidine tract gene [142]. Terminal oligopyrimidine tract is an mRNA cis-regulatory sequence that inhibits translation from mRNA in growth-arrested cells. TMEM18 was also identified as a protein that enhances neural stem cell migration towards gliomas [52]. This action may be correlated with the suppression by TMEM18 of Yin-Yang1, which inhibits expression of genes that were increased in association with the attraction of neural stem cells to gliomas [51]. TMEM18 was also correlated with the tumorigenicity of human tumour-derived cell lines [1]. In addition to these links with cancer biology, TMEM18 has been associated with the age of menarche [90], but the common polymorphisms near to TMEM18 that have been linked to obesity were not associated with either education level or income [44].

In summary, TMEM18 seems likely to play a role in obesity by transcriptional regulation of targets linked either to appetite and energy balance via its central sites of action or through an impact on adipogenesis in the periphery. The largest gaps in our knowledge relate to which genes TMEM18 may be transcriptionally regulating. Construction of transgenic or $\mathrm{KO}$ mice, combined with next-generation sequencing to identify transcrip-

Functional Analysis of 7 Genes Linked to BMI and Adiposity tomic profiles of the genetically manipulated versus wild-type mice, would be a large step forwards to enhance our understanding of its roles. A diagram summarising the potential role of TMEM18 in obesity is shown in figure 7.

\begin{tabular}{|ll|}
\hline SNP & rs9816226 \\
\hline Chromosome & $3 q 28$ \\
BMI link identified in & {$[116]$} \\
Location & Intronic \\
At risk allele & T \\
Nearest gene & ETS variant gene 5 (ETV5) \\
Synonyms & ERM \\
Entrez gene reference & 2119 \\
Ensembl gene reference & ENSG00000244405 \\
\hline
\end{tabular}

The ETS gene family, comprising PEA3 and ER81, was first identified in the early 1990s in mice. These transcription factors share 95\% identity in an 85 amino acid sequence, termed the ETS domain, which is responsible for DNA binding. In 1994, a new member of the family was discovered in humans and was called the ETS-related molecule (ERM) [78]. Gel shift analysis indicated that the full-length ERM protein was able to bind specifically to an oligonucleotide containing the consensus nucleotide core sequence GGAA that is recognised by the other ETS proteins. The gene was found to be almost ubiquitously expressed in normal human tissues, although it was particularly highly expressed in the brain and placenta, and to a lesser degree in the lung, pancreas and heart. In mouse tissues, it was also almost ubiquitously expressed [78]. ERM was subsequently renamed ETV5, although use of both names continues in the literature.

$E R M / E T V 5$ is an oncogene with clear associations to several forms of cancer [reviewed in 85], notably prostate cancer, where chromosomal rearrangements of ERM/ ETV5 (and ETV1 and ETV4) are thought to be one of the main factors in the genesis of prostate tumours. However, it is also implicated in Ewing's sarcoma, breast cancer and melanomas, and seems to be an important factor influencing the progression of endometrial cancer. ERM/ ETV5 has been shown to play a role in the normal development of the lungs [60], the kidney [61] and the limb buds [64]. It also appears to play a key role in normal spermatogenesis [49]. It is expressed in the granulosa and cumulus cells of mouse ovaries, during folliculogenesis, which it controls by regulating cyclooxygenase activity [26]. A promising link between ERM/ETV5 and genes linked to dopamine (DA) signalling was inferred from studies of C. elegans, in which it was shown that the ETS 
Fig. 7. Diagram summarising the effects of

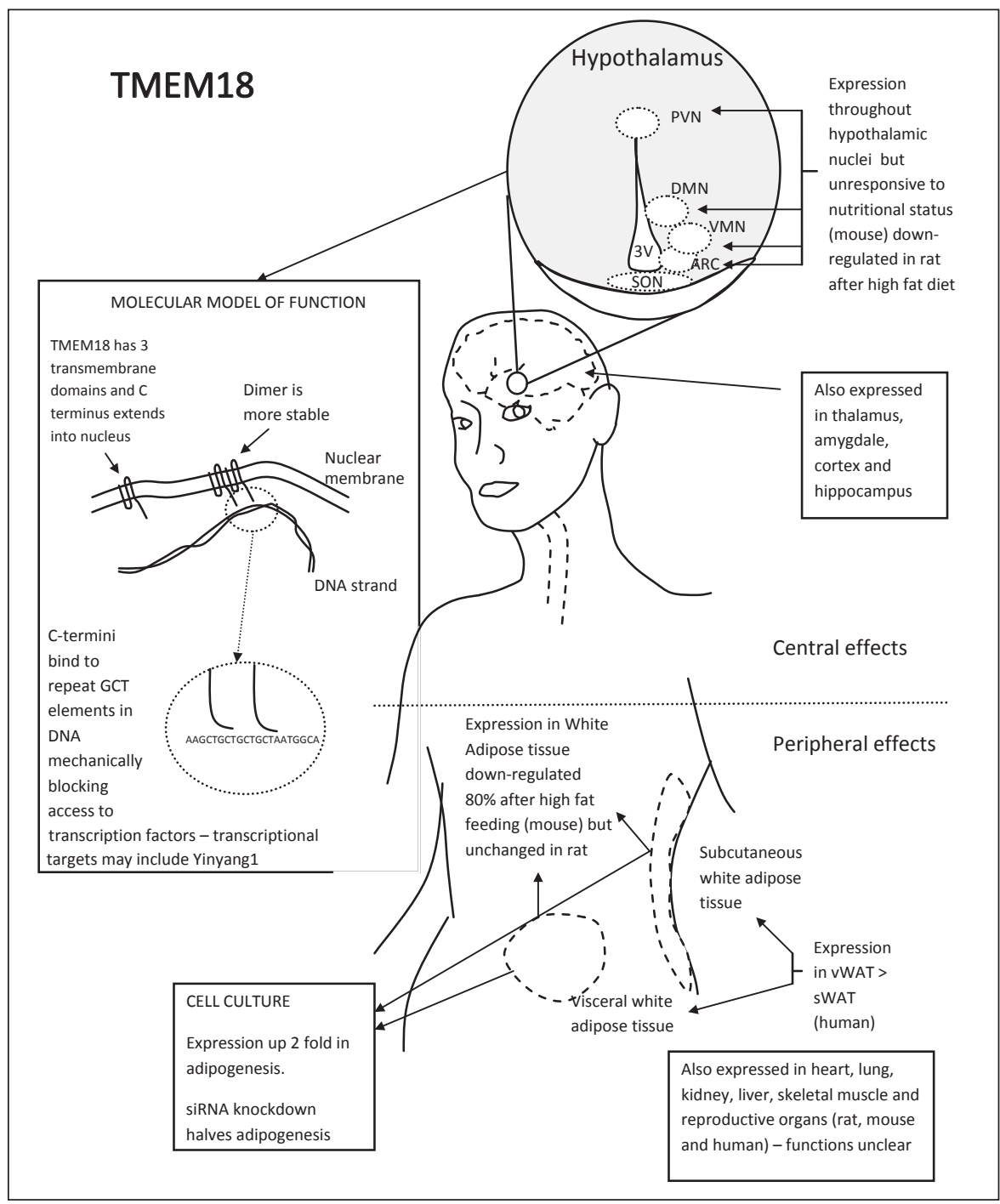
TMEM18 in relation to obesity.

family transcription factor ast- 1 regulates multiple genes comprising the DA neuron phenotype, including biosynthetic enzymes and transporters [30]. DA signalling in the brain has been linked to obesity [131]; hence, if ERM/ ETV5 was involved in the regulation of development of the DA system or regulation of its activity in the adult, this would provide a putative mechanism by which the link to obesity is mediated. This potential role for ERM/ETV5 is supported by the fact that it is highly expressed in the mouse midbrain [133]. However, it was shown in mice that ERM/ETV5 expression is not detectable until postnatal stages in the midbrain, well after development of the DA system [133]. Moreover, ERM/ETV5 KO and control mice show comparable tyrosine hydroxylase and DA transporter expression in the embryonic and adult mid- brain [133]. A link to obesity, via an impact on DA signalling, therefore seems unlikely. However, contrasting this view, nutritional state affected the gene expression levels of ERM/ETV5 in the substantia nigra/VTA in mice [15]. In the hypothalamus, ERM/ETV5 was downregulated in Long-Evans rats following 6 weeks of high-fat feeding, but it was unaffected by $24 \mathrm{~h}$ of starvation [35]. Expression levels in adipose tissue, liver, soleus and extensor digitorum longus (EDL) muscle were unaffected by highfat feeding [35]. Similarly, nutritional state influenced gene expression of ERM/ETV5 in the ventromedial and arcuate nuclei of the hypothalamus in mice [15].

Being a transcription factor, the possibility that ERM/ ETV5 influences energy balance by transcriptional regulation of key genes linked to food intake, in either the hypo- 
thalamus or the substantia nigra/VTA, seems highly likely. For example, the GGAA-binding sequence for ERM/ ETV5 is found in the NPY gene. However, we have no direct evidence for a link between the GWAS-identified SNPs and food intake or energy expenditure in humans. Moreover, despite the fact that mice that have had the $E R M / E T V 5$ gene knocked out have been in existence for at least 3 years [132], their metabolic phenotype with respect to obesity status remains unpublished. Given its wide tissue expression profile, the possibility that ERM/ETV5 also plays a direct role in the periphery cannot be discounted, especially as ERM/ETV5 seems to play a role in the regulation of serum concentrations of adiponectin [17].

\begin{tabular}{|ll|}
\hline SNP & rs2112347 \\
\hline Chromosome & $5 \mathrm{q} 13.3$ \\
BMI link identified in & {$[116]$} \\
Location & Intergenic \\
At risk allele & $\mathrm{T}$ \\
Nearest gene & FLJ35779 \\
Synonyms & Centrosomal protein POC5 \\
Entrez gene reference & 134359 \\
Ensembl gene reference & ENSG00000152359 \\
\hline
\end{tabular}

POC5 is a 575 amino acid protein which appears to play an important role in centriole assembly [10]. Recruitment of POC5 occurs during the G2/M phase and continues up to full centriole maturation during the next cell cycle. Without POC5, RPE1 cells arrest in G1 phase, while HeLa cells show an extended S phase followed by cell death. POC5 does not appear to be needed for initiation of procentriole assembly, but is required for construction of the distal half of centrioles [10]. Apart from the linkage to obesity in GWAS studies, I could find no published literature pertaining to the function of this gene that might link it to obesity risk.

\begin{tabular}{|ll|}
\hline SNP & rs10968576 \\
\hline Chromosome & 9p21.2 \\
BMI link identified in & {$[116]$} \\
Location & Intronic \\
At risk allele & G \\
Nearest gene & Leucine-rich repeat and Ig \\
& domain-containing NOGO \\
& receptor-interacting protein \\
& (LINGO2) \\
Synonyms & LERN3, LRRN6C \\
Entrez gene reference & 158038 \\
Ensembl gene reference & ENSG00000174432 \\
\hline
\end{tabular}

Functional Analysis of 7 Genes Linked to BMI and Adiposity
The LINGO family of genes (also called LERN and LRRIG family members) consists of 4 genes, all of which encode transmembrane proteins containing 12 extracellular leucine-rich repeats, an immunoglobulin $\mathrm{C} 2$ domain and a short intracellular tail. The family member LINGO2/LERN3 that is linked to obesity in GWAS is expressed exclusively in the brain [46]. During embryogenesis in the mouse, LINGO2/LERN3 is expressed in a population of cells lying adjacent to the epithelial lining of the olfactory pit [36]. In the adult mouse brain, it is expressed exclusively in neuronal tissue. The LINGO proteins are known to interact with the NOGO receptor [73], which is involved in the regulation (primarily inhibition) of neurite outgrowth. Inhibition of LINGO1 increases the survival of dopaminergic neurons in models of Parkinson's disease [48]. Variants of LINGO2 have been linked to essential tremor in Parkinson's disease [126, 128]. Hence, a linkage to obesity via interactions with DA signalling seems a possibility. Otherwise, we have very little information about the function of this gene.

\begin{tabular}{|c|c|}
\hline SNP & rs7498665 \\
\hline Other significant nearby & rs147094247, rs8049439, rs4788102, \\
\hline SNPs & $\begin{array}{l}\text { rs7498665, rs60604881, rs62037368, } \\
\text { rs62037369 }\end{array}$ \\
\hline Chromosome & $16 \mathrm{p} 11.2$ \\
\hline BMI link identified in & {$[19,116,137]$} \\
\hline Location & Exonic \\
\hline At risk allele & G \\
\hline Nearest gene & $\begin{array}{l}\text { Src-homology } 2 \mathrm{~B} \text { adaptor protein } 1 \\
\text { (SH2B1) }\end{array}$ \\
\hline Synonyms & PSM SHB-2 KIAA1299 \\
\hline Entrez gene reference & 25970 \\
\hline Ensembl gene reference & ENSG00000178188 \\
\hline
\end{tabular}

The $\mathrm{SH} 2 \mathrm{~B}$ adaptor protein 1 (SH2B1) is unusual among the genes linked to obesity via GWAS, because the main identified SNP is exonic. The SNP rs7498665 is non-synonymous and leads to an alanine to threonine amino acid substitution at residue 484 of the 767 AA protein. SH2B1 can be spliced in four different ways, generating $\alpha, \beta, \gamma$ and $\delta$ forms [96]. It is also unusual among the genes reviewed here in that a clear functional link of the gene to signalling systems related to energy balance and obesity was well established before the gene was identified as being associated to BMI and adiposity by the GWAS. SH2B1 is expressed in numerous mouse tissues, including the brain, hypothalamus, liver, muscle, adipose tissue, heart and pancreas $[54,96]$, with different splice variants being differently represented in the different tissues [96]. 
In humans, expression was highest in the skeletal muscle, pituitary gland, lymphocytes, kidneys, ovaries and pancreas (fig. 1) [13]. Expression in the brain and hypothalamus was below the median expression across all tissues, which is surprising in the light of previous studies relating to its function as a modulator of the JAK-STAT signalling pathway.

The Janus kinase (JAK)/signal transducer and activator of transcription (STAT) pathway is a major intracellular signalling pathway that links cell surface receptors to transcriptional targets in the nucleus. This includes multiple hormones and cytokines, including the receptors for growth hormone $(\mathrm{GH})$, leptin, insulin and erythropoietin. JAK is a tyrosine kinase that can bind to the intracellular domain of cytokine and other receptors. When the receptor binds to its ligand, the JAK protein is activated, resulting in phosphorylation of tyrosine residues on the receptor by JAK. Proteins that contain phosphotyrosine Src homology 2 ( $\mathrm{SH} 2$ ) domains can bind to these sites. One class of proteins containing such sites are the STAT proteins. Once bound to the receptor, the STAT proteins can themselves be phosphorylated by JAK at tyrosine residues, allowing other STAT proteins to recruit onto them, and then dimerise and release from the receptor. These dimerised STAT proteins can then translocate to the nucleus, where they initiate transcription. There are 5 STAT proteins, and hence a variety of alternate dimer products, that can initiate transcription at a range of different transcriptional targets.

The JAK-STAT pathway is negatively regulated by two sets of molecules. The suppressors of cytokine signalling (SOCS) are transcriptionally activated by STAT proteins, and once translated, the mature SOCS proteins compete with STAT for phosphotyrosine binding sites or reduce signalling by inhibiting JAK protein activity. Alternatively, protein tyrosine phosphatases (PTPs) can inhibit signalling by dephosphorylating the sites phosphorylated by JAK. In contrast, the pathway activity can be enhanced by another family of molecules, which themselves contain $\mathrm{SH} 2$ homology domains, called the $\mathrm{SH} 2$ adaptor proteins. These include APS (later renamed SH2B2), Lnk (renamed SH2B3) and SH2-B or PSM [99] (later renamed SH2B1). SH2B1 binds to unphosphorylated JAK at the leptin receptor (in the absence of leptin), via its non-SH2 domain regions. The mechanism by which $\mathrm{SH} 2 \mathrm{~B} 1$ enhances the activity of JAK is by performing a common adaptor protein role, whereby it helps to recruit target proteins to the receptor (e.g. STATs). However, SH2B1 also appears able to directly enhance the kinase activity of JAK proteins by up to 20 -fold $[66,105]$.
JAK2 has a total of 49 tyrosines in the mouse [103], which, if auto-phosphorylated, could also serve as docking sites for SH2 domain-containing molecules. When leptin binds to its receptor, it stimulates phosphorylation of tyrosine residue 813 on JAK2, which subsequently binds to the SH2 domain of SH2B1 [58]. This binding of SH2B1 to JAK2, at tyrosine 813, enhances the leptin induction of JAK2 activity. It has been suggested that phosphorylation of tyrosines 868, 966 and 972 in the kinase domain of JAK2 is required for JAK2 to retain maximal kinase activity [8]. This is based on the observation that JAK2, lacking tyrosines at either 868,966 or 972 , has substantially reduced activity. However, co-expression with $\mathrm{SH} 2 \mathrm{~B} 1 \beta$ partially restores the activity of all three JAK2 mutants. Based on these results and the crystal structure of the JAK2 kinase domain, Argetsinger et al. [8] suggested that small conformation changes of JAK2, adjacent to tyrosines 868, 966 and 972 , may be essential for JAK2 to assume a maximally active conformation. These small conformation changes may include phosphorylation, binding to a ligand-bound cytokine receptor and binding to SH2B1. This ability of SH2B1 to directly enhance the kinase activity of JAK appears to be unique among adaptor proteins [66].

The long form of the leptin receptor (LepR-b) is a type 2 cytokine receptor with an intracellular domain that is linked to a JAK2-STAT3 signalling cascade. Given that $\mathrm{SH} 2 \mathrm{~B} 1$ is a positive regulator of this signalling pathway, it is not surprising that mice with the SH2B1 gene knocked out had impaired leptin signalling, resulting in obesity, hyperlipidaemia and leptin resistance $[79,95,96]$ (fig. 8). Food intake was increased by about $60 \%$ in the $\mathrm{KO}$ animals [95]. In addition to this increase in food consumption, there was also an unexpected increase of oxygen consumption per gram of tissue in the $\mathrm{KO}$ compared to the wild-type animals [95]. Ren et al. [95] suggested that, despite the elevated energy expenditure, the KO mice were still in a state of greater positive energy balance than control wild types, explaining their greater obesity. However, the calculations of the energy imbalance of the KO animals ( $15 \mathrm{kcal}$ per day) are at odds with the rise in body weight. If the mice really were consuming $15 \mathrm{kcal}$ per day more than they expended, then one would expect them to increase in mass by over $1 \mathrm{~g}$ per day, yet over the 20 weeks (140 days) from age 7 to 27 weeks, the mice increased by only $40 \mathrm{~g}$. Even assuming the calculated intake did not account for faecal and urinary losses does not account for the difference.

The data on food intake and energy expenditure in Ren et al. [96] are even less clear. In this case, food intake
Speakman 
Fig. 8. Body weight change of male and female wild-type $(+/+)$ mice and mice with whole-body $\mathrm{KO}$ of the SH2B1 gene $(-/-)$. Knocking out the gene leads to the development of severe obesity in both sexes [from 95].
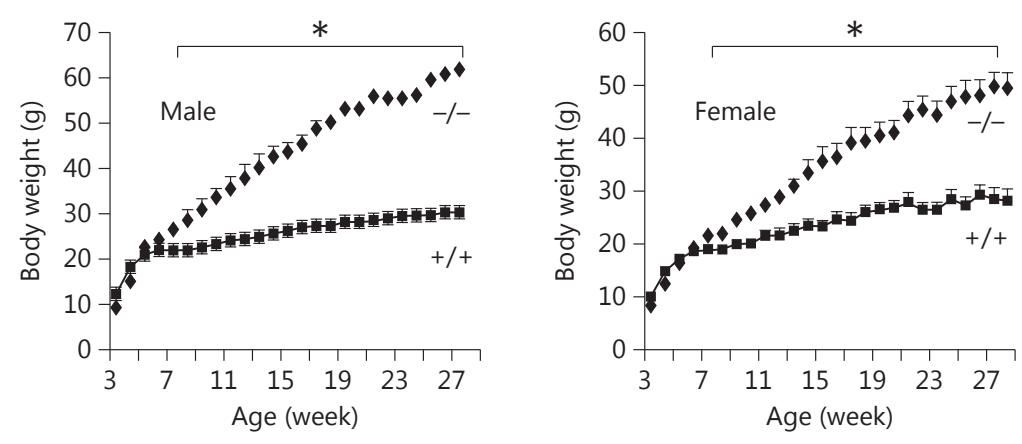

of the $\mathrm{KO}$ animals increased by about $30 \%$, but their energy expenditure (per gram) almost doubled. The estimated energy expenditure for the two groups derived from data in the figures shows that the wild-type mice were in positive energy balance (intake about $20.8 \mathrm{kcal} /$ day compared to an expenditure of about $14.5 \mathrm{kcal} /$ day), but the $\mathrm{KO}$ animals were not (intake of about $26.5 \mathrm{kcal} /$ day and expenditure of about $35.2 \mathrm{kcal} /$ day). The data collected by Morris et al. [79] have a similar anomaly (for wild type, intake of about $18 \mathrm{kcal} /$ day against an expenditure of about $13 \mathrm{kcal} /$ day and in the $\mathrm{KO}$ mice, an intake of about $26 \mathrm{kcal} /$ day against an expenditure of about 31 $\mathrm{kcal} /$ day). Clearly, more data are required to establish exactly how an energy imbalance leading to obesity develops in these mice.

The impairment in the $\mathrm{KO}$ mice resulting in obesity is exclusively a consequence of the loss of SH2B1 in the brain $[79,96]$. Ren et al. [96] created transgenic mice expressing rat $\mathrm{SH} 2 \mathrm{~B} 1 \beta$ in the brain and crossed these with a whole-body $\mathrm{KO}$ mouse to generate mice expressing $\mathrm{SH} 2 \mathrm{~B} 1$ only in neural tissue. Neuron-specific restoration of $\mathrm{SH} 2 \mathrm{~B} 1 \beta$ not only corrected the metabolic disorders in constitutive $\mathrm{KO}$ mice, but also improved JAK2-mediated leptin signalling and leptin regulation of orexigenic neuropeptide gene expression in the hypothalamus. Moreover, neuron-specific overexpression of SH2B1 protected against high-fat diet-induced leptin resistance and obesity, via a normalisation of both food intake and energy expenditure (oxygen consumption) to levels observed in wild-type animals fed chow diet. Morris et al. [79] illustrated the same phenomenon by generating three different lines of mice, expressing wild-type, $\mathrm{SH} 2$ domain-defective (R555E) or SH2 domain-alone (Delta N503) forms of SH2B1, specifically in neurons. These mice were then crossed with $\mathrm{SH} 2 \mathrm{~B} 1 \mathrm{KO}$ mice to generate $\mathrm{KO} / \mathrm{SH} 2 \mathrm{~B} 1$,
$\mathrm{KO} / \mathrm{R} 555 \mathrm{E}$, or KO/Delta N503 compound mutant mice. In these mice, there was no peripheral SH2B1, but various forms of neuronal SH2B1. Neuron-specific expression of wild-type SH2B1, but not R555E or Delta N503, corrected hyperphagia, obesity, glucose intolerance and insulin resistance in SH2B1 null mice. These data showed that the effects of knocking out SH2B1 globally were entirely due to its central actions. Moreover, since the Delta N503 construct did not rescue the obesity phenotype, these data indicated that, in addition to the $\mathrm{SH} 2$ domain, $\mathrm{N}$-terminal regions of neuronal $\mathrm{SH} 2 \mathrm{~B} 1$ are also required for the maintenance of normal body weight and glucose metabolism.

In addition to the common polymorphisms identified by GWAS, a number of rare loss-of-function mutations have also been identified in the $S H 2 B 1$ gene in humans $[23,127]$ as well as in a number of patients with large deletions of sections of chromosome 16 that encompass the gene $[14,130]$. All cases, carriers of the loss-of-function mutations as well as cases with gene absence, exhibited hyperphagia, childhood onset obesity, disproportionate insulin resistance and reduced final height as adults. The effect on energy intake was consistent with data from 1,700 Dutch females where the 'at risk' SNP in SH2B1 was linked with increased fat consumption [12].

Given this background, the role of impairments of this gene in causing obesity would appear to be clear. Impaired SH2B1 removes the enhancement of intracellular leptin signalling in the brain, leading to a blunting of the downstream response to leptin (leptin resistance), which generates hyperphagia and hence obesity. However, that said, the role of the specific exonic SNP mutation identified by GWAS, and the other GWAS SNPs that are intronic or intergenic, is far less clear. First, the exonic SNP-driven protein modification does not localise to the $\mathrm{SH} 2$ domain, where an impact on binding to 
JAK might be anticipated. Given the finding that other parts of the molecule may also be linked to its function as an enhancer molecule $[79,96]$, this is not completely surprising. Nevertheless, the JAK2-STAT3-mediated leptin signalling of HEK293 cells carrying the Ala464Thr SNP in vitro was not impaired compared to the wildtype control [127]! Rather surprisingly, it was also found that nutritional state had no effect on the gene expression levels of SH2B1 in the ventromedial and arcuate nuclei of the hypothalamus (and the substantia nigra/ VTA) in the mouse [15]. This suggests there may be a much more subtle impact of the gene on energy balance, the details of which we are currently unaware. These could conceivably include actions in the periphery or on brain development.

In the periphery, $S H 2 B 1$ plays a major role in insulin signalling, as might be expected given the fact that JAKSTAT signalling is also an intracellular signalling pathway used by the insulin receptor. SH2B1 ( $\alpha$ ) is highly expressed in the pancreas as well as the liver, skeletal muscle and adipose tissue, which are the major sites of insulin action. Early work suggested that SH2B1 does not bind directly to phosphorylated tyrosine residues on the insulin receptor substrate (IRS) proteins [54]. Instead, it was suggested that the protein interacted with the activation loop of the receptor [54]. This suggestion was supported by work showing that a panel of single-point mutants of the activation loop, specifically $\operatorname{Tyr}(1158)$, $\operatorname{Tyr}(1162)$ and $\operatorname{Tyr}(1163)$, all abolished interaction with $\mathrm{SH} 2 \mathrm{~B} 1$. It has also been suggested that the primary association between $\mathrm{SH} 2 \mathrm{~B} 1$ is at the $\mathrm{C}$ terminus $[99,132]$. Nevertheless, later studies suggested that the protein does bind directly to IRS-1 and IRS-2, as well as to the insulin receptor itself [80], and the binding to IRS- 1 and IRS-2 was stimulated by insulin. In mice, where the peripheral SH2B1 was knocked out but the brain expression was intact, there were profound negative effects on insulin signalling across multiple tissues [80]. The knockon effect of this impairment was that deletion of peripheral SH2B1 markedly exacerbated high-fat diet-induced hyperglycaemia, hyperinsulinemia and glucose intolerance.

In vitro, the deletion of $\mathrm{SH} 2 \mathrm{~B} 1$ impaired insulin signalling in primary hepatocytes, whereas $\mathrm{SH} 2 \mathrm{~B} 1$ overexpression stimulated insulin receptor auto-phosphorylation and tyrosine phosphorylation of IRSs. The SH2 domain of SH2B1 was required, and sufficient, to promote insulin receptor activation [22]. The physical interaction between SH2B1 and the IRS proteins inhibited tyrosine dephosphorylation of IRS-1 or IRS-2 and thereby in- creased the ability of the IRS proteins to activate the phosphatidylinositol 3-kinase (PI3K) pathway. The polymorphism rs7359397, identified by GWAS, has been linked to variation in the HOMA index of insulin sensitivity [28].

$\mathrm{SH} 2 \mathrm{~B} 1$ also seems to play an important role as a modulator of nerve growth via an interaction with nerve growth factor (NGF) receptor [94]. NGF is essential for the development and survival of sympathetic and sensory neurons. NGF binds to the TrkA receptor, activates the intrinsic kinase activity of TrkA and promotes the differentiation of pheochromocytoma (PC12) cells into sympathetic-like neurons. In culture, overexpression of $\mathrm{SH} 2 \mathrm{~B} 1$ with the SH2 domain mutated blocked NGF-induced neurite outgrowth of PC12 cells. In contrast, overexpression of wild-type SH2B1 enhanced NGF-induced neurite outgrowth [104]. Interestingly, the overexpression of either wild type or the mutated SH2B1 did not alter tyrosine phosphorylation of TrkA, Shc or phospholipase $\mathrm{C} \gamma$ in response to NGF, or modulate NGF-induced activation of ERK1/2. This suggested that $\mathrm{SH} 2 \mathrm{~B} 1$ was not interacting with the NGF receptor in the same way that it interacts with cytokine receptors, like the leptin receptor (detailed above). Supporting the suggestion that SH2B1 acts with a different mechanism with respect to NGF, depleting endogenous $\mathrm{SH} 2 \mathrm{~B} 1$ using short hairpin RNA inhibited NGF-dependent neurite outgrowth in PC12 cells, but had no effect on NGF-mediated phosphorylation of the downstream intracellular signals Akt or ERKs $1 / 2$ [67]. In fact, SH2B1 has a nuclear localisation signal in its sequence [67]. Mutation of this signal had no effect on NGF-induced activation of TrkA and ERKs 1/2, but prevented $\mathrm{SH} 2 \mathrm{~B} 1 \beta$ from enhancing NGF-induced neurite outgrowth. It thus appeared that $\mathrm{SH} 2 \mathrm{~B} 1$ was acting as a transcription factor, shuttling into the nucleus to directly activate transcription [67]. Supporting this view, disruption of the $\mathrm{SH} 2 \mathrm{~B} 1 \beta$ nuclear import signal also prevented SH2B1 $\beta$ from enhancing NGF-induced transcription of genes, which are important for neuronal differentiation [67]. Phosphorylation of serine residues in the vicinity of the nuclear localisation sequence is important in regulating its cellular location [68].

SH2B1 enhances neurite outgrowth in at least three other ways. First, it acts as an adapter protein for FGFmediated neurite outgrowth and glial cell line-derived neurotrophic factor (GDNF)-induced neurite outgrowth by prolonging both FGF and GDNF signalling [59]. In addition, $\mathrm{SH} 2 \mathrm{~B} 1$ plays a role in the regulation of $\mathrm{N}$-cadherin, a molecule known to be involved in the engagement between cells that contributes to neuronal migra- 
tion. Overexpression of $\mathrm{SH} 2 \mathrm{~B} 1 \beta$ reduced $\mathrm{N}$-cadherin levels and increased phosphotyrosine $654 \beta$-catenin, leading to increased NGF-induced neurite initiation in PC12 cells [134]. In contrast, overexpression of the mutant SH2B1 lacking the $\mathrm{SH} 2$ domain increased $\mathrm{N}$-cadherin expression, cell-cell aggregation, and reduced neurite initiation. SH2B1 seemed to do this by binding directly to the $\mathrm{N}$ cadherin [134].

Given its critical role as an enhancer protein on a wide variety of receptors, it is unsurprising that $\mathrm{SH} 2 \mathrm{~B} 1$ has been implicated in several other physiological and disease processes. These include the regulation of bone mineral density [141], cancer [146], erythropoiesis [50], prolactin signalling [98] and hence control of the actin cytoskeleton [97]. Unexpectedly, carriers of the loss-of-function mutations linked to obesity also exhibited a spectrum of behavioural abnormalities that were not reported in controls, including social isolation and aggression [23].

In summary, there is considerable evidence showing that $\mathrm{SH} 2 \mathrm{~B} 1$ acts as an adaptor protein that enhances signalling in the JAK-STAT pathway, downstream of the leptin receptor. In the hypothalamus, this action enhances leptin signalling and protects against obesity development. Knocking out the gene in animals or natural lossof-function mutations in humans both lead to elevated food intake and severe obesity associated with leptin resistance. The impact of the $\mathrm{KO}$ on energy expenditure is unclear. Moreover, the functions of the specific polymorphisms identified by GWAS remain less certain. In cell culture, the 'at risk' SNP did not appear to affect leptin signalling via the JAK-STAT pathway, as might have been anticipated. The gene also plays a role as an enhancer of insulin signalling, downstream of the insulin receptor, and in neurite outgrowth, due to multiple actions including a role as a transcription factor, downstream of the nerve growth receptor (NGR). Hence, it could play a role in the development of the neural circuitry controlling feeding behaviour. Carriers of the 'at risk' SNP appear to have increased food consumption. However, it would not be surprising, given its role in mediating the responses of both leptin and insulin receptors, if it was shown to also play a significant role in adipogenesis. The gene was neither up- nor downregulated during adipogenesis [13]. This does not necessarily suggest that it has no role, since its hypothalamic expression status was also unresponsive to nutritional state [15] and it undoubtedly plays an important part in the control of food intake. A diagram summarising the functions of $\mathrm{SH} 2 \mathrm{~B} 1$ in relation to obesity is shown in figure 9.

Functional Analysis of 7 Genes Linked to BMI and Adiposity

\begin{tabular}{|c|c|}
\hline SNP & rs2287019 \\
\hline Chromosome & $19 q 13.32$ \\
\hline BMI link identified in & {$[76,102]$} \\
\hline Location & Intronic \\
\hline At risk allele & $\mathrm{C}$ \\
\hline Nearest gene & $\begin{array}{l}\text { Gastric inhibitory polypeptide } \\
\text { receptor (GIPR) }\end{array}$ \\
\hline Synonyms & $\begin{array}{l}\text { Glucose-dependent insulinotropic } \\
\text { polypeptide receptor, gut-derived } \\
\text { nutrient intake polypeptide receptor }\end{array}$ \\
\hline Entrez gene reference & 2696 \\
\hline Ensembl gene reference & ENSG00000010310 \\
\hline
\end{tabular}

Discovered in 1971 [18], GIP was originally called the gastric inhibitory polypeptide, but it is more recently referred to as the glucose-dependent insulinotropic polypeptide. It is a $40 \mathrm{AA}$ incretin hormone secreted by the duodenal endocrine $\mathrm{K}$ cells [93]. Like the other main incretin hormone, GLP-1, it mediates enhanced release of insulin from the pancreas [24] in response to high levels of glucose (or fat) in the duodenum. The receptor for this hormone (GIPR) is a G-protein coupled receptor, primarily localised to $\beta$ cells in the pancreatic islets, where it exerts its insulinotropic action. Knocking out the GIPR gene in mice resulted in greater levels of circulating glucose and an impaired immediate response to an oral glucose load, which is consistent with its role as an incretin [77]. However, the overall impact on glucose tolerance was relatively modest, due in part to compensatory increases in the activity of the GLP1 signalling pathway, related to altered islet structure [88]. Surprisingly, knocking out both GIPR and GLP-1R in the same mouse did not produce a more profound glucose intolerance, indicating other compensatory measures are also enabled [38]. In all these cases, the genetically manipulated mice had a normal body weight phenotype.

Extrapancreatic populations of the receptor are also found in the brain, on bone and on adipocytes [139], and, as might be expected, in these other locations, it exerts rather different effects. Miyawaki et al. [76] showed that GIPR KO mice fed on a high-fat diet were resistant to weight gain. Moreover, when the mice were cross-bred with ob/ob mice lacking functional leptin, which normally become profoundly obese, the extent of weight and adiposity gain was blunted. In part, this was because the GIPR KO mice used fat as a preferred energy substrate (reflected in a lowered respiratory quotient). Similar results were found in the double $\mathrm{KO}$ animals with loss of both GIPR and GLP-1R [38]. In addition to the switch towards greater fat oxidation in these double $\mathrm{KO}$ mice, they also exhibited increased energy expenditure linked 
Fig. 9. Diagram summarising the effects of

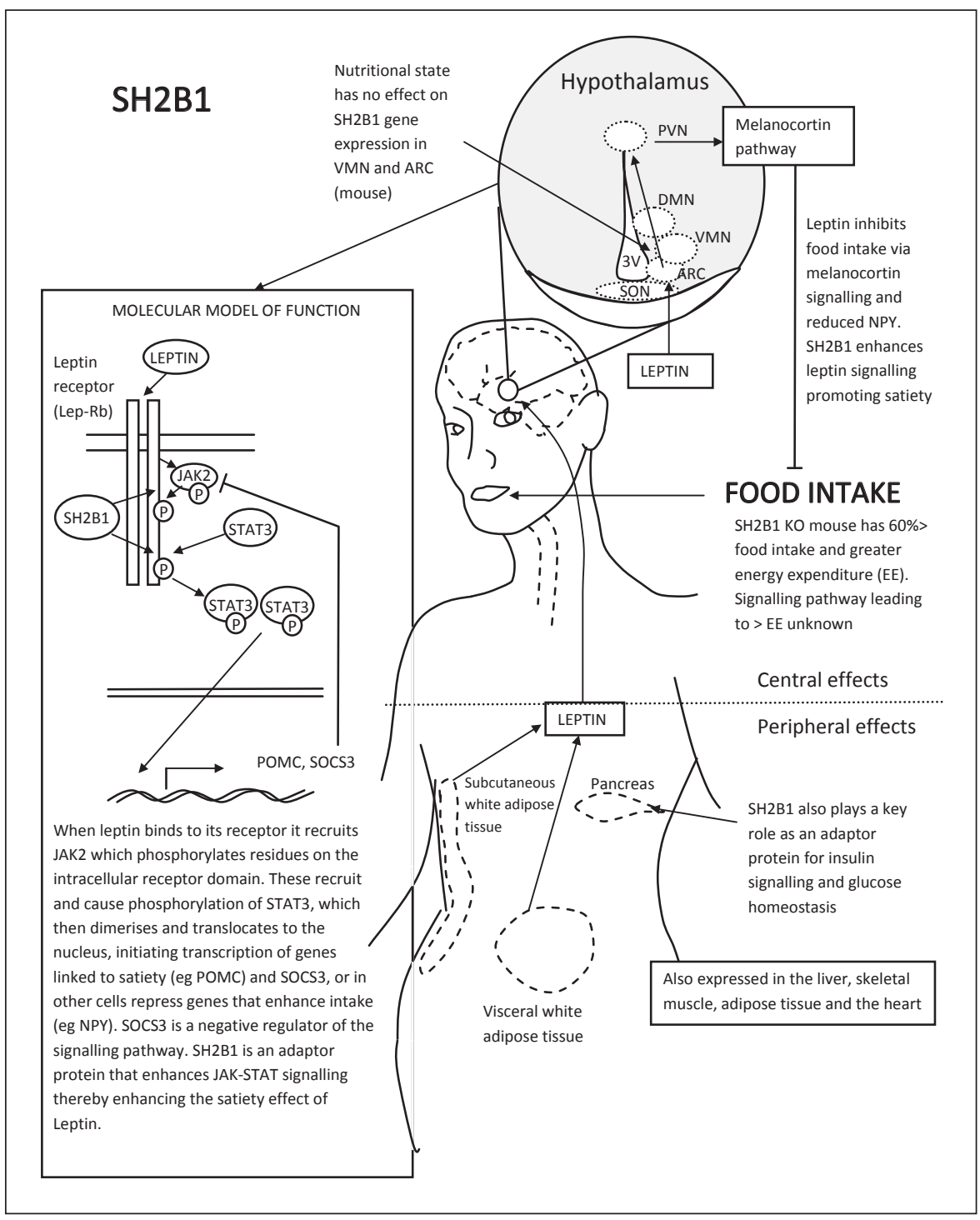
$\mathrm{SH} 2 \mathrm{~B} 1$ in relation to obesity.

to greater physical activity levels [39]. Yamada et al. [140] showed that this elevated physical activity in GIPR KO mice was maintained throughout life and protected these mice from the age-associated increase in body fatness and its consequences for age-related insulin resistance. Consistent with the maintained lower body fatness, the levels of adiponectin were greater in the GIPR KO mice [140]. This elevation of adiponectin levels in GIPR KO mice has been suggested to be instrumental in driving both the increase in energy expenditure and fat oxidation in skeletal muscle [81]. In addition to these genetic manipulations, several other papers have pointed to an effect of GIPR in the regulation of body weight and fatness. For example, administration of GIPR peptide antagonists [69], im- munisation against GIP [32] or ablation of the intestinal $\mathrm{K}$ cell where GIP is produced [4] all result in protection against high-fat feeding-induced weight gain.

There are two main potential mechanisms through which intact GIPR may promote obesity in the face of feeding on a high-fat diet. GIPR on the adipocytes may act to enhance uptake and storage of circulating triglycerides, matched with a stimulation of adipogenesis. Several lines of evidence support such a direct role. In culture, GIP inhibits lipolysis [34, 43], acting via adipocytespecific receptors $[101,144]$. However, in vivo, the action may be indirect and mediated via the GIPR stimulation of insulin, which then promotes adipogenesis and fat uptake. Indeed, the stimulation of lipid uptake by GIP in 


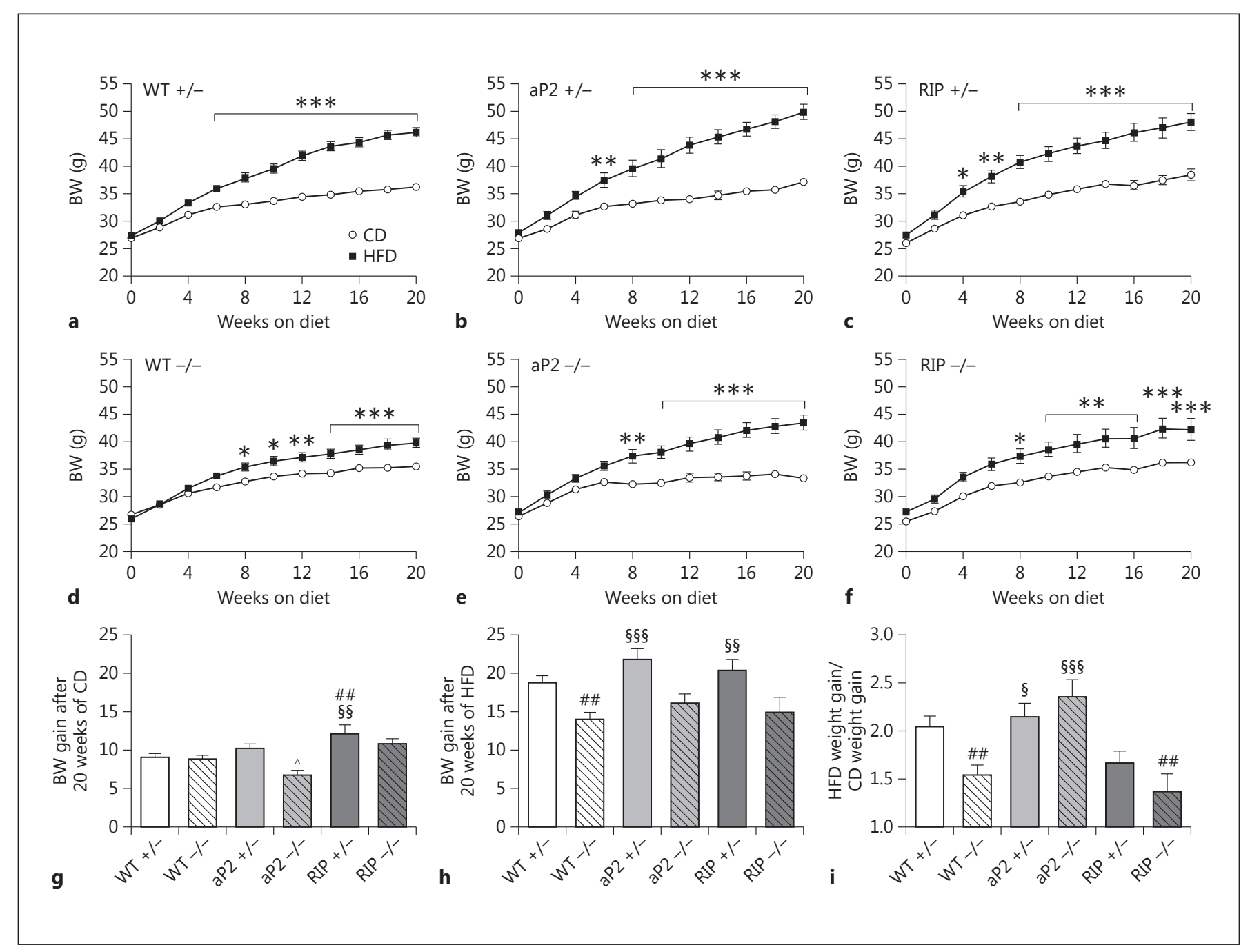

Fig. 10. Effects of expressing human GIPR in the adipose tissue $(\mathrm{aP} 2+/-)$ or $\beta$ cells $(\mathrm{RIP}+/-)$ of mice that had endogenous GIPR knocked out (WT-/-). The aP2 (-/-) and RIP (-/-) are mice null for human GIPR and mouse GIPR. Weight gain on a high-fat diet was reduced when the GIPR was knocked out (compare $\mathbf{a}$ and $\mathbf{d}$ ). Repletion of the GIPR in either the adipocyte $(\mathbf{b}, \mathbf{e})$ or in the $\beta$ cell

culture is enhanced when insulin is present [43], indicating both actions may play a role. To address this issue in vivo, mice were generated that had targeted tissue-specific expression of human GIPR in only the adipocytes $(\mathrm{aP} 2+/-)$ or in only the $\beta$ cells (RIP $+/-)$ [123]. By crossing these mice with GIPR KO mice, they generated mice that expressed human GIPR in adipocytes or $\beta$ cells only. It was suggested from these data that mice with active GIPR in adipocytes gained weight at the same rate as controls, when fed a high-fat diet, and at a significantly higher rate than the weight gain of the global KO animals. However, (c, f) removed this protection from diet-induced obesity [from 123]. $\mathrm{BW}=$ Body weight $\mathrm{CD}=$ control diet $\mathrm{HFD}=$ high-fat diet. ${ }^{*} \mathrm{p}<0.05,{ }^{* *} \mathrm{p}<0.01,{ }^{* * *} \mathrm{p}<0.001$, HFD versus CD; ${ }^{\# \#} \mathrm{p}<0.01$, versus WT $(+/-)$ fed the same diet; ${ }^{\S} \mathrm{p}<0.05,{ }^{\S \S} \mathrm{p}<0.01,{ }^{\S \S \S} \mathrm{p}<$ 0.001 , versus WT (-/-) fed the same diet; ${ }^{\wedge} \mathrm{p}<0.05$, aP2 $-/$ - versus $\mathrm{aP} 2+/-$. mice with expression of GIPR only in the $\beta$ cells did not gain weight to the same extent. These interpretations, however, depend very critically on how the weight gain was expressed. The above interpretations were generated by dividing the weight gain when fed the high-fat diet by the weight gain when fed the control diet (fig. 10i) [123]. However, this approach generates an anomalous result, because the response to the high-fat diet in this case is greatest in the aP2-/- mice, which should have no active GIPR of either human or mouse origin and hence should not differ from the wild-type $\mathrm{KO}$ animals. This difference 
seems to be an artefact of dividing by the slightly lower weight gain of the mice on the control diet. Equally, the low gain of the RIP (+/-) mice (expressing human GIPR on the $\beta$ cells) seems only to be generated by the slightly higher rate of weight gain in the controls. If one examines just the weight gain after 20 weeks of high-fat diet feeding (fig. 10h), then it is clear that the weight gains of the mice without the human or mouse GIPR (i.e. WT-/-, aP2-/and RIP-/-) were all similar (see also fig. 10d-f). In contrast, the weight gains of the mice either with intact native GIPR in all tissues (WT+/-), human GIPR in adipose tissue $(\mathrm{aP} 2+/-)$ or human GIPR in $\beta$ cells $(\mathrm{RIP}+/-)$ were also all similar (see also fig. $10 \mathrm{a}-\mathrm{c}$ ). This suggests that both direct and indirect modes of action for GIPR on fat storage play an important role.

Ugleholdt et al. [123] additionally suggested that the differences in weight gain on a high-fat diet were due to differences in lean rather than fat tissue (see original paper fig. 3), although this again relies on dividing the changes under high-fat feeding by those observed under the control diet, which produces similar anomalous high responses in the aP2-/- group. In contrast, using the raw data for the response to a high-fat diet alone indicates that the $\mathrm{WT}+$ /-, aP2+/- and RIP+/- groups have consistently gained 4-5 g more body fat under a high-fat diet when compared with the WT-/-, aP2-/- and RIP-/- animals, respectively, suggesting that at least $50 \%$ of the impact of a high-fat diet on total weight gain was contributed to by differences in fat mass. While impacts on lean mass clearly also contribute to the total weight change, these do not explain the entire impact on adiposity.

An impact of GIP on bone would be anticipated because it stimulates insulin production, which influences bone formation and mineralisation [125]. However, GIPR are also found on osteoblasts [16], suggesting that GIP may also have a direct role in bone metabolism. Indeed, treatment of cultured osteoblasts stimulates cellular events linked with bone formation. This might be significant since bone metabolism contributes to total energy metabolism and hence may influence energy balance. An impact of GIPR loss on bone metabolism in vivo was first shown in the GIPR KO mouse [138]. These mice had reduced bone size, lower bone mass, altered bone microarchitecture and biomechanical properties, and altered parameters for bone turnover, especially bone formation. In addition, the mice had earlier age-related changes than wild-type mice in body composition, including bone mass. Tsukiyama et al. [120] suggested that these effects occurred because GIP (acting on GIPR in bone) directly influences calcium uptake into bone, facilitating utilisa- tion of dietary calcium in circulation, which is normally elevated after a meal.

These responses then suggest that GIP, in concert with GIPR, plays a general role in facilitating the utilisation of ingested nutrients. This includes increasing insulin to dispose of ingested glucose, increasing fat uptake into adipocytes and stimulating adipogenesis, and finally stimulating calcium uptake and bone formation in bony tissue. In fact, on this basis, it has been suggested that it would be better called gut-derived nutrient intake polypeptide [139]. In addition to these effects, GIP seems to have an impact on appetite via GIPR receptors in the brain. In humans, where insulin was clamped, intraduodenal glucose infusion led to a rise in GIP, followed by GLP-1 [55]. Decreases in appetite were closely linked to GLP-1 levels. Subsequent data indicated that because GLP-1 is rapidly degraded before it reaches the systemic circulation, this action is probably because GLP-1 stimulates sensory afferents in the gastrointestinal mucosa, which signal to both the brain stem and hypothalamus [45]. Nevertheless, direct infusions of physiologically relevant levels of GLP-1 were effective in reducing appetite [31], pointing to a dual mechanism. In contrast, GIP infusion in humans also impacted appetite sensations, but in the opposite direction [20]. This increase in appetite occurred despite the fact that it was later shown that GIP infusion in humans probably decreases production of ghrelin [102], another gut hormone that is produced by the stomach, and stimulates appetite. Unexpectedly, GIP infusion also caused a reduction in metabolic rate [20].

In the brain, GIPR is expressed in the hypothalamus, hippocampus and cortex [111]. GIPR KO mice have impaired learning abilities, particularly related to defects in spatial learning and memory as evaluated by the Morris water maze [27]. Infusion of GIP into the hypothalamus of rats for 4 days resulted in upregulation of hypothalamic mRNA levels of several genes related to food intake and energy balance, including AVP, CART, NPY, OXT and STAT3 [5]. In GIPR KO mice, gene expression of AVP, CART, OXT and STAT3 in the hypothalamus were downregulated relative to wild-type mice [5]. These data suggest that stimulation of AVP and NPY may underpin the stimulatory effect of infused GIP on appetite [20]. The positive impact on CART and OXY levels, however, is confusing, because CART and OXT are anorexigenic agents.

Like SH2B1, GIPR is unusual among the genes linked to BMI and adiposity by GWAS studies in that a clear link to obesity was established before the gene was identified by GWAS. The manner in which the intronic SNP influences the impact of GIPR remains uncertain. However, it 
Fig. 11. Diagram summarising the effects of GIPR in relation to obesity.

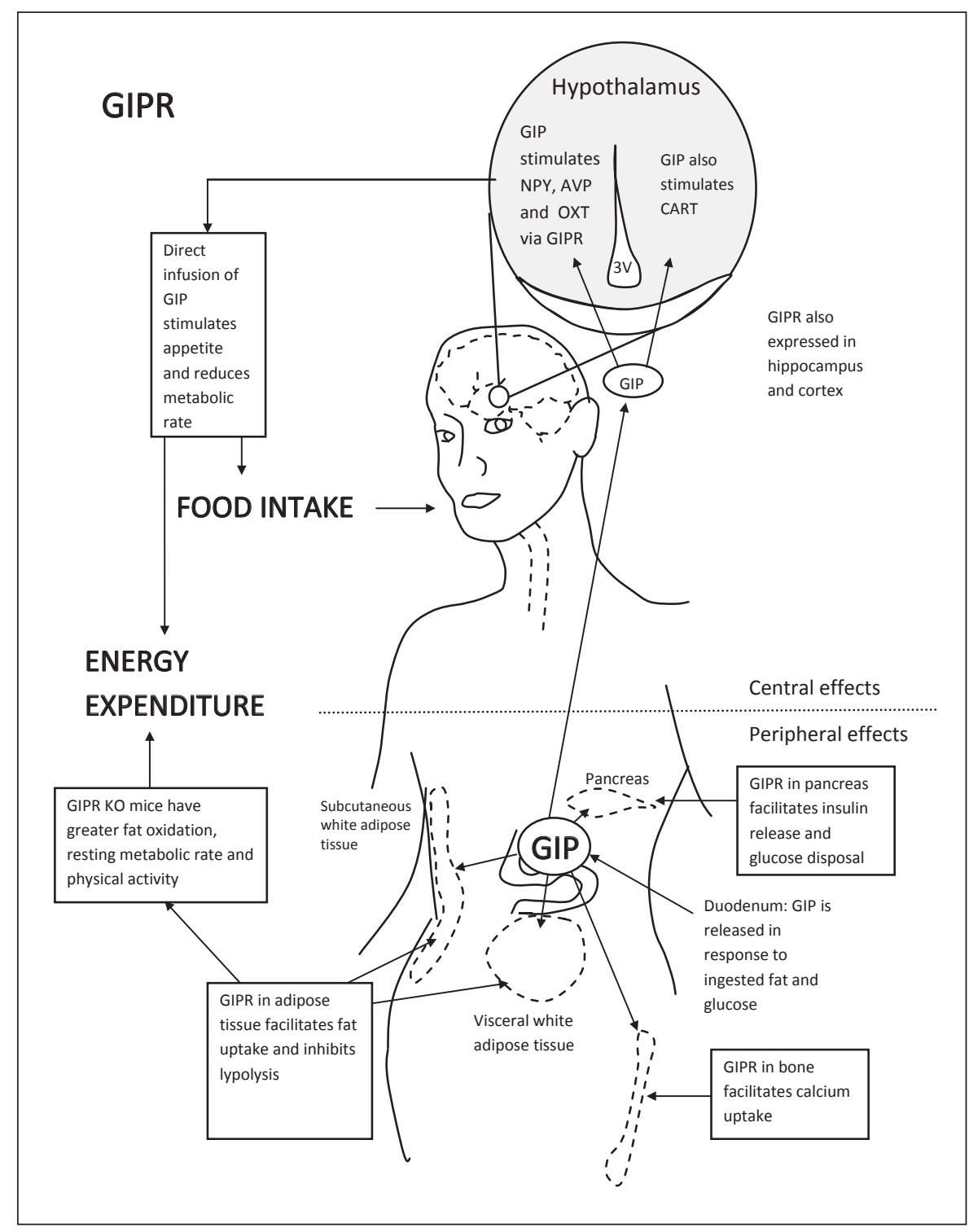

seems likely that some impact on the ability of the receptor to stimulate adipogenesis and fat uptake, or on the actions of the GIP hormone in the brain on appetite, are probable. The effect on energy expenditure remains paradoxical and still requires a mechanistic explanation. A summary of the effects of GIPR in relation to obesity is offered in figure 11 .

\section{Conclusions}

Of the 7 genes reviewed here, only 2 had clear associations with obesity before the advent of the GWAS studies. Even in these 2 genes, where we know something about how they influence energy balance and fat storage, the mechanism(s) by which the specific polymorphisms identified by GWAS act to cause weight gain remain unclear. For the other genes, where a linkage to obesity was not previously obvious, we are even less able to specify how the association comes about. All 7 genes are expressed in the brain. Two of these, SH2B1 and GIPR, have been linked directly to appetite regulation. However, 3 of the genes (NEGR1, SH2B1 and LINGO2) have also been implicated in neurite outgrowth. Therefore, rather than a direct contribution as part of the appetite signalling system, SNPs nearby these genes may primarily contribute to weight regulation and obesity by influencing the devel- 
opment of the energy balance regulatory circuits in the brain - and hence the polymorphisms may effectively be silent in adulthood. In spite of this apparent domination of central effects [see also 87, 139], it has recently become clear that all of these targets, where we have any detailed information, have complex functions in multiple tissues. Notably, 4 of the genes (Kilon/NEGR1, TMEM18, SH2B1 and GIPR) are also expressed in adipocytes. It could well be that the SNPs in the neighbourhood of these genes exert their actions via effects on the peripheral gene functions, rather than the central functions. Such action outside of the hypothalamus has also recently been inferred for the effect of FTO on body composition [70].

\section{Acknowledgements}

I am grateful to David Allison and John Dawson for the invitation to contribute to this special issue. During the production of this review, I was supported by both a ' 1000 talents' Professorship from the Chinese Government and also a CAS-Novo Nordisk Foundation 'Great Wall' Professorship, for which I am thankful. Catherine Hambly and two anonymous referees made many helpful corrections and suggestions that improved the manuscript.

\section{References}

1 Abdullah NM, Rosania GR, Shedden K: Selective targeting of tumorigenic cancer cell lines by microtubule inhibitors. PLoS One 2009; 4:e4470.

-2 Adeymo A, Gerry N, Chen GJ, et al: A genome wide association study of hypertension and blood pressure in African Americans. PLoS Genet 2009;5:e1000564.

- 3 Almèn MS, Jacobsson JA, Shaik JH, Olszewski PK, Cedernaes J, et al: The obesity gene, TMEM18, is of ancient origin, found in majority of neuronal cells in all major brain regions and associated with obesity in severely obese children. BMC Med Genet 2010;11:58.

4 Althage MC, Ford EL, Wang S, Tso P, Polonsky KS, Wice BM: Targeted ablation of glucose-dependent insulinotropic polypeptide-producing cells in transgenic mice reduces obesity and insulin resistance induced by a high fat diet. J Bio Chem 2008;283:18365-18376.

5 Ambati S, Duan J, Hartzell DL, et al: GIP dependent expression of hypothalamic genes. Physiol Res 2011;60:941-950.

-6 Aoyagi T, Kusakawa S, Sanbe A, et al: Enhanced effect of neuropeptide $\mathrm{Y}$ on food intake caused by blockade of the V-1A vasopressin receptor. Eur J Pharmacol 2009;622: 32-36.

-7 Arch JRS, Hislop D, Wang SJY, Speakman JR: Some mathematical and technical issues in the measurement and interpretation of opencircuit indirect calorimetry in small animals. Int J Obes 2006;30:1322-1331.

-8 Argetsinger LS, Stuckley JA, Robertson SA, et al: Tyrosines 868, 966 and 972 in the kinase domain of JAK2 are autophosphorylated and required for maximal JAK2 kinase activity. Mol Endocrinol 2010;24:1062-1076.

-9 Arletti R, Benelli A, Bertolini A: Influence of oxytocin on feeding behavior in the rat. Peptides 1989;10:89-93.

10 Azimzadeh J, Hergert P, Delouvee A, Euteneuer U, Formstecher E, Khodjakov A, Born- ens $\mathrm{M}$ : hPOC5 is a centrin-binding protein required for assembly of full length centrioles. J Cell Biol 2009;185:101-114.

11 Bauer AU, Savasan NE, Plaschke, et al: IGmolecule Kilon shows a differential expression pattern from LAMP in the developing and adult rat hippocampus. Hippocampus 2000;10:632-644

12 Bauer F, Elbers CC, Adan RAH, Loos RJF, Onland-Moret NC, et al: Obesity genes identified in genome-wide association studies are associated with adiposity measures and potentially with nutrient-specific food preference. Am J Clin Nutr 2009;90:951-959.

13 Bernhard F, Landgraf K, Kloeting N, et al: Functional relevance of genes implicated by obesity genome-wide association study signals for human adipocyte biology. Diabetologia 2013;56:311-322.

14 Bochukova EG, Huang N, Keogh J, et al: Large rare chromosomal deletions associated with severe early onset obesity. Nature 2010;463: 666-670.

15 Boender AJ, van Rozen AJ, Adan RAH, et al: Nutritional state affects the expression of obesity associated genes Etv5, Faim2, Fto and Negr1. Obesity 2012;20:2420-2425.

16 Bollag RJ, Zhong Q, Ding KH, et al: Glucose dependent insulinotropic peptide is an integrative hormone with osteotropic effects. Mol Cell Endocrinol 2001;177:35-41.

17 Breitfield J, Stumvoll M, Kovacs P: Genetics of adiponectin. Biochimie 2012;94:2157-2163.

18 Brown JC, Dryburgh JR: A gastric inhibitory polypeptide. II. The complete amino acid sequence. Can J Biochem 1971;49:867-872.

19 Burton PR, Clayton DG, Cardon LR, et al: Genome wide association study of 14,000 cases of seven common diseases and 3,000 shared controls. Nature 2007;447:661-678.

20 Daousi C, Wilding JPH, Aditya S, et al: Effects of peripheral administration of synthetic human glucose-dependent insulino- tropic peptide (GIP) on energy expenditure and subjective appetite sensations in healthy normal weight subjects and obese patients with type 2 diabetes. Clin Endocrinol 2009; 71:195-201.

21 Day FR, Loos RJF: Developments in obesity genetics in the era of genome-wide association studies. J Nutrigenet Nutrogenomics 2011;4:222-238.

22 Deblon N, Veyrat-Durebex C, Bourgoin L, et al: Mechanisms of the anti-obesity effects of oxytocin in diet-induced obese rats. PLoS One 2001;6:e25565.

23 Doche ME, Bochukova EG, Su HW, et al: Human SH2B1 mutations are associated with maladaptive behaviours and obesity. J Clin Invest 2012;122:4732-4736.

24 Dupre J, Ross SA, Watson D, Brown JC: Stimulation of insulin secretion by gastric inhibitory polypeptide in man. J Clin Endocrinol Metab 1973;37:826-828.

25 Eeles RA, Kote-Jarai Z, Giles GG, et al: Multiple newly identified loci associated with prostate cancer susceptibility. Nat Genet 2008;40:316-321.

26 Eo J, Han KY, Murphy KM, et al: Etv5 and ETS transcription factor is expressed in granulose and cumulus cells and serves as a transcriptional regulator of cyclooxygenase-2. J Endocrinol 2008;198:281-290.

27 Faivre E, Gault VA, Thorens B, et al: Glucosedependent insulinotropic polypeptide receptor knockout mice are impaired in learning, synaptic plasticity, and neurogenesis. J Neurophysiol 2011;105:1574-1580.

28 Fall T, Arnlov J, Berne C, Ingelsson E: The role of obesity-related genetic loci in insulin sensitivity. Diabet Med 2012;29:E62-E66.

29 Fox CS, Liu YM, White CC, et al: Genomewide association for abdominal subcutaneous and visceral adipose reveals a novel locus for visceral fat in women. PLoS Genet 2012; 8:e1002695 
-30 Flames N, Hobert O: Gene regulatory logic of dopamine neuron differentiation. Nature 2009;458:885-889.

31 Flint A, Tangaa W, Rugbjerg K, et al: The effect of GIP on postprandial appetite and energy expenditure. Int J Obes 2004;28:S168.

- 32 Fulurija A, Lutz TA, Sladko K, Osto M, Wielinga PY, Nachman MF, Saudan P: Vaccination against GIP for the treatment of obesity. PLoS One 2008;3:e3163.

33 Funatsu N, Miyata S, Kumanogoh H, et al: Characterisation of a novel rat brain glycosylphosphatidylinositol-anchored protein (KILON), a member of the IgLON cell adhesion molecule family. J Biol Chem 1999;274: 8224-8230.

-34 Getty-Kaushik L, Song DH, Boylan MO, Corkey BE, Wolfe MM: Glucose-dependent insulinotropic polypeptide modulates adipocyte lipolysis and reesterification. Obesity 2006; 14:1124-1131.

35 Gutierrez-Aguilar R, Kim DH, Woods SC, Seeley RJ: Expression of new loci associated with obesity in diet-induced obese rats: from genetics to physiology. Obesity 2012;20:306312.

36 Haines BP, Rigby PWJ: Expression of the lingo/LERN family during mouse embryogenesis. Gene Expr Patterns 2008;8:79-86.

- 37 Hall KH, Heymsfield S, Kemnitz J, Klein S, Schoeller DA, Speakman JR: Energy balance and body weight regulation: a useful concept for understanding the obesity epidemic. Am J Clin Nutr 2012;95:989-994.

38 Hansotia T, Baggio LL, Delmeire D, et al: Double incretin receptor knockout (DIRKO) mice reveal an essential role of the enteroinsular axis in transducing the glucoregulatory actions of DPP-IV inhibitors. Diabetes 2004 53:1326-1335.

-39 Hansotia T, Maida A, Flock G, et al: Extrapancreatic incretin receptors modulate glucose homeostasis, body weight and energy expenditure. J Clin Invest 2007;117:143-152.

40 Harold D, Abraham R, Hollingworth P, et al: Genome wide association study identifies variants at CLU and PICALM associated with Alzheimer's disease. Nat Genet 2009;41: 1088-1093.

41 Hashimoto T, Maekawa S, Miyata S: IgLON cell adhesion molecules regulate synaptogenesis in hippocampal neurons. Cell Biochem Funct 2009;27:496-498.

42 Hashimoto T, Yamada M, Maekawa S, Nakashima T, Miyata S: IgLON cell adhesion molecule Kilon is a crucial modulator for synapse number in hippocampal neurons. Brain Res 2008;1224:1-11.

-43 Hauner H, Glatting G, Kaminska D, Pfeiffer EF: Effects of gastric inhibitory polypeptide on glucose and lipid metabolism of isolated rat adipocytes. Ann Nutr Metab 1998;32:282288.

44 Holzapfel C, Grallert H, Baumert J, Thorand B, Döring A, Wichmann HE, Hauner H, Illig T, Mielck A: First investigation of two obesity-related loci (TMEM18, FTO) concerning their association with educational level as well as income: the MONICA/KORA study. J Epidemiol Community Health 2011;65:174-176.

45 Holst JJ: On the physiology of GIP and GLP-1. Horm Metab Res 2004;36:11-12.

-46 Homma S, Shimada T, Hikake T, Yaginuma $\mathrm{H}$ : Expression pattern of LRR and Ig domaincontaining protein (LRRIG protein) in the early mouse embryo. Gene Expr Patterns 2009;9:1-26.

47 Hunter DJ, Kraft P, Jacobs KB, et al: A genome-wide association study identifies alleles in FGFR2 associated with risk of sporadic postmenopausal breast cancer. Nat Genet 2007;39:870-874

48 Inoue $\mathrm{H}$, Lin L, Lee X, et al: Inhibition of the leucine-rich repeat protein LINGO-1 enhances survival, structure, and function of dopaminergic neurons in Parkinson's disease models. Proc Natl Acad Sci USA 2007;104: 14430-14435.

49 Ishii K, Kanatsu-Shinohara M, Toyokuni S, et al: FGF2 mediates mouse spermatogonial stem cell self-renewal via upregulation of Etv5 and Bcl6b through MAP2K1 activation. Development 2012;139:1734-1743.

50 Javadi M, Hofstaetter E, Stickle N, et al: the SH2B1 adapter protein associates with a proximal region of the erythropoietin receptor. J Biol Chem 2012;287:26223-26234.

51 Jurvansuu JM, Goldman A: Obesity risk gene TMEM18 encodes a sequence specific DNA binding protein. PLoS One 2011;6:e25317.

52 Jurvansuu J, Zhao Y, Leung DS, Boulaire J, Yu YH, Ahmed S, Wang S: Transmembrane protein 18 enhances the tropism of neural stem cells for glioma cells. Cancer Res 2008; 68: 4614-4622.

53 Kohno D, Nakata M, Maejima Y, et al: Nesfatin-1 neurons in paraventricular and supraoptic nucleus of the rat hypothalamus co-express oxytocin and vasopressin and are activated by refeeding. Endocrinology 2008; 149 : 1295-1301.

54 Kotani K, Wilden P, Pillay TS: SH2-B is an insulin-receptor adaptor protein and substrate that interacts with the activation loop of the insulin receptor kinase. Biochem J 1998; 335:103-109.

55 Lavin JH, Wittert GA Andrews J, et al: Interaction of insulin, glucagon like peptide 1, gastric inhibitory polypeptide and appetite. Am J Clin Nutr 1998;68:591-598.

56 Lee AWS, Hengstler H, Swald K, et al: Functional inactivation of the genome wide association study obesity gene neuronal growth regulator 1 in mice causes a body mass phenotype. PLoS One 2012; 7:e 41537.

57 Levy D, DeStefano AL, Larson MG, et al: Evidence for a gene influencing blood pressure on chromosome 17. Genome scan linkage results for longitudinal blood pressure phenotypes in subjects from the Framingham Heart study. Hypertension 2000;36:477-483.

58 Li Z, Zhou YJ, Carter-Su C, et al: SH2B1 enhances leptin signalling by both Janus-Kinase $2 \operatorname{Tyr}(813)$ phosphorylation dependent and independent mechanisms. Mol Endocrinol 2007;21:2270-2281.

59 Lin WF, Chen CJ, Chang YJ, et al: SH2B1 $\beta$ enhances fibroblast growth factor 1 (FGF1)induced neurite outgrowth through MEKERK1/2-STAT3-Egr1 pathway. Cell Signal 2009;21:1060-1072.

60 Liu YR, Jiang HY, Crawford HC, Hogan BLM: Role for ETS domain transcription factors Pea3/Erm in mouse lung development. Dev Biol 2003;261:10-24.

61 Lu BC, Cebrian C, Chi X, Kuure S, Kuo R, et al: Etv4 and Etv5 are required downstream of GDNF and Ret for kidney branching morphogenesis. Nat Genet 2009;41:1295-1302.

62 Ma M, Harding HP, O'Rahilly S, et al: Kinetic analysis of FTO (fat mass and obesity-associated) reveals that it is unlikely to function as a sensor for 2-oxoglutarate. Biochem J 2012; 444:183-187.

63 Maejima Y, Ieasaki Y, Yamahara Y, et al: Peripheral oxytocin treatment ameliorates obesity by reducing food intake and visceral fat mat. Aging 2011;3:1169-1177.

64 Mao JH, McGlinn E, Huang P, Tabin CJ, McMahon AP: Fgf-dependent Etv4/5 activity is required for posterior restriction of sonic hedgehog and promoting outgrowth of the vertebrate limb. Dev Cell 2009;16:600-606.

65 Marg A, Sirim P, Spaltmann F, et al: Neurotractin a novel neurite outgrowth-promoting Ig-like protein that interacts with CEPU-1 and LAMP. J Cell Biol 2009;145:865-876.

66 Maures TJ, Kurzer JH, Carter-Su C: Sh2B1 (SH2-B) and Jak2: a multifunctional adaptor protein and kinase made for each other. Trends Endocrinol Metab 2007;18:38-45.

67 Maures TJ, Chen LY, Carter-Su C, et al: Nucleocytoplasmic shuttling of the adapter protein $\mathrm{SH} 2 \mathrm{~B} 1$ beta (SH2-B beta) is required for nerve growth factor (NGF) dependent neurite outgrowth and enhancement of expression of a subset of NGF-responsive genes. Mol Endocrinol 2009;23:1077-1091.

68 Maures TJ, Su HW, Argetsinger LS, et al Phosphorylation controls a dual-function polybasis nuclear localisation sequence in the adapter protein $\mathrm{SH} 2 \mathrm{~B} 1$ beta to regulate its cellular function and distribution. J Cell Sci 2011;124:1542-1552.

69 MaClean PL, Irwin N, Cassidy RS, Holst JJ, Gault VA, Flatt PR: GIP receptor antagonism reverses obesity, insulin resistance and associated metabolic disturbances induced in mice by prolonged consumption of high-fat diet. Am J Physiol 2007;293:E1746-E1755.

70 McMurray F, Church CD, Larger R, Nicholson $\mathrm{G}$, et al: Adult onset global loss of the Fto gene alters body composition and metabolism in the mouse. PLoS Genet 2013; 9:e1003166

71 McNamee CJ, Reed JE, Howard MR, Lodge AP, Moss DJ: Promotion of neuronal cell adhesion by members of the IgLON family occurs in the absence of either support or modification of neurite outgrowth. Neurochemistry 2002;80:941-948. 
-72 McPherson R, Pertsemlidis A, Kavaslar N, et al: A common allele on chromosome 9 associated with coronary heart disease. Science 2007;316:1488-1491.

73 Mi S, Lee X, Shao ZH, et al: LINGO-1 is a component of the NOGO-66 receptor/p75 signalling complex. Nat Neurosci 2004;7: 221-228.

-74 Miyata S, Matsumoto N, Taguchi K, Akagi A, Iino T, Funatsu N, Maekawa S: Biochemical and ultrastructural analyses of IgLON cell adhesion molecules, Kilon and OBCAM in the rat brain. Neuroscience 2003;117:645-658.

-75 Miyata S, Taguchi K, Maekawa S: Dendriteassociated opioid-binding cell adhesion molecule localizes at neurosecretory granules in the hypothalamic magnocellular neurons. Neuroscience 2003;122:169-181.

-76 Miyawaki K, Yamada Y, Ban N, et al: Inhibition of gastric inhibitory polypeptide signalling prevents obesity. Nat Med 2002;8:738-742.

77 Miyawaki K, Yamada Y, Yano H, et al: Glucose intolerance caused by a defect in the entero-insular axis: a study in gastric inhibitory polypeptide receptor knockout mice. Proc Natl Acad Sci USA 1999;96:14843-14847.

-78 Monté D, Baert JL, Defossez PA, de Launoit Y, Stéhelin D: Molecular cloning and characterization of human ERM, a new member of the ETS family closely related to mouse PEA3 and ER81 transcription factors. Oncogene 1994;9:1397-406.

79 Morris DL, Cho KW, Rui LY: Critical role of the Src Homology 2 (SH2) domain of neuronal SH2B1 in the regulation of body weight and glucose homeostasis in mice. Endocrinology 2010;151:3643-3651.

80 Morris DL, Cho KW, Zhou YJ, et al: SH2B1 enhances insulin sensitivity by both stimulating the insulin receptor and inhibiting tyrosine dephosphorylation of insulin receptor substrate proteins. Diabetes 2009;58:20382047.

81 Naitoh R, Miyawaki K, Harada N, et al: Inhibition of GIP signalling modulates adiponectin levels under high fat diet in mice. Biochem Biophys Res Commun 2008;376:21-25.

82 Newson MJF, Roberts EM, Pope GR, et al: The effects of apelin on hypothalamic-pituitary-adrenal axis neuroendocrine function are mediated through corticotrophin releasing factor and vasopressin dependent mechanisms. J Neuroendocrinol 2009;202:123-129.

-83 Newton-Cheh C, Johnson T, Gateva V, et al: Genome-wide association study identifies eight loci associated with blood pressure. Nat Genet 2009;41:666-676.

84 Oh S, Shimizu H, Satoh T, et al: Identification of nesfatin- 1 as a satiety molecule in the hypothalamus. Nature 2006;443:709-712.

-85 Oh S, Shin S, Janknect R: ETV1, 4 and 5: an oncogenic subfamily of ETS transcription factors. Biochim Biophys Acta 2012;1826:1-12.

-86 Okada Y, Kubo M, Ohmiya H, et al: Common variants at CDKAL1 and KLF9 are associated with body mass index in east Asian populations. Nat Genet 2012;44:302-306.
87 O’Rahilly S, Farooqi IS: Human obesity as a heritable disorder of the central control of energy balance. Int J Obes 2008;32:S55S61.

88 Pamir N, Lynn FC, Buchan AMJ, et al: Glucose dependent insulinotropic polypeptide receptor null mice exhibit compensatory changes in the enteroinsular axis. Am J Physiol 2003;284:E931-E939.

89 Paternoster L, Evans DM, Nohr EA, et al: Genome wide population based association study of extremely overweight young adults - the GOYA study. PLoS One 2012;6:e24303.

90 Perry JRB, Stolk L, Franceschini N, et al: Meta-analysis of genome-wide association data identifies two loci influencing age at menarche. Nat Genet 2009;41:648-650.

-91 Pietrobelli A, Faith MS, Allison DB, et al: Body mass index as a measure of adiposity among children and adolescents: a validation study. J Pediatr 1998;132:204-210.

92 Pillai SG, GE DL, Zhu GH, et al: A genome wide association study in chronic obstructive pulmonary disease (COPD): identification of two major susceptibility loci. PLoS Genet 2009;5:e1000421.

-93 Polak JM, Bloom SR, Kuzio M, Brown JC, Pearse AGE: Cellular localisation of gastric inhibitory polypeptide in the duodenum and jejunum. Gut 1973;14:284-288.

-94 Qian XZ, Riccio A, Zhang Y, et al: Identification and characterisation of novel substrates of $\operatorname{TrK}$ receptors in developing neurons. Neuron 1998;21:1017-1029.

95 Ren D, Li M, Duan C, Rui LY: Identification of SH2-B as a key regulator of leptin sensitivity, energy balance, and body weight in mice. Cell Metab 2005;2:95-104.

\$6 Ren DC, Zhou YJ, Morris D, Li MH, Li ZQ, Rui LY: Neuronal SH2b1 is essential for controlling energy and glucose homeostasis. J Clin Invest 2007;117:397-406.

97 Rider L, Tao J, Snyder S, et al: Adapter protein $\mathrm{SH} 2 \mathrm{~B} 1$ beta cross links actin filaments and regulates actin cytoskeleton. Mol Endocrinol 2009;23:1055-1076.

98 Rider L, Diankonova M: Adapter protein SH2B1 beta binds filamin A to regulate prolactin dependent cytoskeltal reorganisation and cell motility. Mol Endocrinol 2011;25: 1231-1243.

-99 Riedel H, Wang J, Hansen H, et al: PSM, an insulin-dependent, pro-rich, $\mathrm{PH}, \mathrm{SH} 2$ domain containing partner of the insulin receptor. J Biochem 1997;122:1105-1113.

100 Romero-Corral A, Somers VK, Sierra-Johnson J, et al: Accuracy of body mass index in diagnosing obesity in the adult general population. Int J Obes 2008;32:959-966.

101 Rudovich NN, Kaiser S, Engeli S, Osterhoff M, Gogebakan O, Bluher M, Pfeiffer AF: Gastric inhibitory polypeptide receptors are presented in human subcutaneous adipose tissue: effects of central obesity and weight loss. Diabetes 2005;54:A364.

102 Rudovich NN, Nikiforova VJ, Otto B, et al: Metabolomic linkage reveals functional in- teraction between glucose-dependent insulinotropic polypeptide and ghrelin in humans. Am J Physiol 2011;301:E608E617.

103 Rui LY, Mathews LS, Hotta K, et al: Identification of SH2-B beta as a substrate of the tyrosine kinase JAK2 involved in growth hormone signalling. Mol Cell Biol 1997;17: 6633-6644.

104 Rui LY, Herrington J, Carter-Su C: Sh2-B is required for nerve growth factor induced neuronal differentiation. J Biol Chem 1999; 274:10590-10594.

105 Rui LY, Carter-Su C: Identification of SH2-B beta as a potent cytoplasmic activator of the tyrosine kinase Janus kinase 2. Proc Nat Acad Sci 1999;96:7172-7177.

106 Satake W, Nakabayashi Y, Mizuta I, et al: Genome-wide association study identifies common variants at four loci as genetic risk factors for Parkinson's disease. Nat Genet 2009;41:1303-1307.

107 Sato K, Takahashi T, Kobayashi Y, et al: Apelin is involved in postprandial responses and stimulates secretion of arginine-vasopressin, adrenocorticotrophic hormone and growth hormone in the ruminant. Domest Anim Endocrinol 2012;42:165-172.

108 Saxena R, Voight BF, Lyssenkov, et al: Genome wide association analysis identifies loci for type 2 diabetes and triglyceride levels. Science 2007;316:1331-1336.

109 Schafer M, Brauer AU, Savaskan NE, Rathjen FG, Brummendorf T: Neurotractin/kilon promotes neurite outgrowth and is expressed on reactive astrocytes after entorhinal cortex lesion. Mol Cell Neurosci 2005;29:580-590.

110 Schmid PM, Heid I, Buechler C, Steege A, et al: Expression of fourteen novel obesity-related genes in Zucker diabetic fatty rats. Cardiovasc Diabetol 2012;11:48.

111 Scott LJ, Mohlke KL, Bonny castle LL, et al: A genome wide association study of type 2 diabetes in Finns detects multiple susceptibility variants. Science 2007;316:889894.

112 Seshadari S, Fitzpatrick AL, Ikram MA, et al: Genome wide analysis of genetic loci associated with Alzheimer disease. JAMA 2010; 303:1832-1840.

113 Simon-Sanchez J, Schulte C, Bras JM, et al: Genome-wide association study reveals genetic risk underlying Parkinson's disease. Nat Genet 2009;41:1308-1312.

114 Shimizu H, Ohsaki A, Oh IS, Okada S, Mri M: A new anorexigenic protein, nesfatin- 1 . Peptides 2009;30:995-998.

115 Sladek R, Rochelau G, Rung J, et al: A genome wide association study identifies novel risk factors for diabetes. Nature 2007;445: 881-885.

116 Speliotes EK, Willer CJ, Berndt SI, Monda KL, Thorleifsson G, et al: Association analyses of 249,796 individuals reveal 18 new loci associated with body mass index. Nat Genet 2010;42:937-948. 
117 Takayanaki Y, Kashahara Y, Onaka T, et al: Oxytocin receptor deficient mice developed late onset obesity. Neuroreport 2008;19: 951-955.

118 Thomas G, Jacons KB, Yaeger M, et al: Multiple loci identified in genome wide association study of prostate cancer. Nat Genet 2008;40:310-315.

-119 Tschop MH, Speakman JR, Arch JRS, et al: A guide to analysis of mouse energy metabolism. Nat Methods 2012;9:57-63.

120 Tsukiyama K, Yamada Y, Yamada C, et al: Gastric inhibitory polypeptide is an endogenous factor promoting new bone formation after food ingestion. Mol Endocrinol 2006; 20:1644-1651

-121 Tung YCL, Ma M, Piper S, Coll A, O’Rahilly S, Yeo GSH: Novel leptin regulated genes revealed by transcriptional profiling of the hypothalamic paraventricular nucleus. J Neurosci 2008;28:12419-12426.

122 Tung YC, Yeo GS: From GWAS to biology: lessons from FTO. Ann NY Acad Sci 2011; 1220:162-171.

123 Ugleholdt R, Pedersen J, Bassi MR, et al: Transgenic rescue of adipocyte glucose-dependent insulinotropic polypeptide receptor expression restores high fat diet induced body weight gain. J Biol Chem 2011;286: 44632-44645.

124 Vermurugan S, Russell JA, Leng G: Systemic leptin increases the electrical activity of supraoptic nucleus oxytocin neurons in virgin and late pregnant rats. J Neuroendocrinol 2013;25:383-390.

125 Verhaeghe J, Suiker AMH, Visser WJ, et al: The effects of systemic insulin, insulin like growth factor 1 and growth hormone on bone growth and turnover in spontaneously diabetic BB rats. J Endocrinol 1992;134:485492.

126 Vilarino-Guell C, Wider C, Ross OA, et al: Lingo1 and Lingo2 variants are associated with essential tremor and Parkinson disease. Neurogenetics 2010;11:401-408.
127 Volckmar AL, Bolze F, Jarick I, et al: Mutation screen in the GWAS derived obesity gene $\mathrm{SH} 2 \mathrm{~B} 1$ including functional analysis of detected variants. BMC Med Genet 2012;5: 65.

128 Wu YW, Prakash KM, Rong TY, et al: Lingo2 variants associated with essential tremor and Parkinson's disease. Hum Genet 2011; 129:611-615.

129 Walley AJ, Jacobson P, Falchi M, Bottolo L, et al: Differential coexpression analysis of obesity-associated networks in human subcutaneous adipose tissue. Int J Obes 2012;36: 137-147.

130 Walters RG, Jacquemont S, Valsesia A, et al: A new highly penetrant form of obesity due to deletions on chromosome $16 \mathrm{p} 11.2$. Nature 2010;463:671-675.

131 Wang GJ, Volkw ND, Logan J, et al: Brain dopamine and obesity. Lancet 2001;357: 354-357.

132 Wang J, Riedel H: Insulin like growth factor-1 receptor and insulin receptor association with a Src homology-2 domain containing putative adapter. J Biol Chem 1998;273: 3136-3139.

133 Wang SR, Turner EE: Expression of dopamine pathway genes in the midbrain is independent of known ETS transcription factor activity. J Neurosci 2010;30:9224-9227.

134 Wang TC, Li YH, Chen KW, et al: SH2B1 beta regulates $\mathrm{N}$-cadherin, cell-cell adhesion and nerve growth factor induced neurite initiation. J Cell Physiol 2011;226:2063-2074.

135 Weedon MN, Lango H, Lindgren CM, et al: Genome wide association analysis identifies 20 loci that influence adult height. Nat Genet 2008;41:575-583.

136 Wen WQ, Cho YS, Zheng W, et al: Metaanalysis identifies common variants associated with body mass index in east Asians. Nat Genet 2012;44:307-311.

137 Willer CJ, Speliotes EK, Loos RJ, Li S, Lindgren CM, et al: Six new loci associated with body mass index highlight a neuronal influence on body weight regulation. Nat Genet 2009;41:25-34.
38 Xie D, Cheng H, Hamrick M, et al: Glucose dependent insulinotropic polypeptide receptor knockout mice have altered bone turnover. Bone 2005;37:759-769.

139 Yamada Y, Miyawaki K, Tsukiyama K, et al: Pancreatic and extrapancreatic effects of gastric inhibitory polypeptide. Diabetes 2006;55:S86-S91.

140 Yamada C, Yamada Y, Tsukiyama K, et al: Genetic inactivation of GIP signalling reverses aging associated insulin resistance through body composition changes. Biochem Biophys Res Commun 2007;364:175180.

141 Yamada Y, Ando F, Shimokata H: Association of genetic variants of MAOA and SH2B1 with bone mineral density in community-dwelling Japanese women. Mol Med Rep 2008;1:269-274.

142 Yamashita R, Suzuki Y, Takeuchi N, Wakaguri $\mathrm{H}$, Ueda $\mathrm{T}$, et al: Comprehensive detection of human terminal oligo-pyrimidine (TOP) genes and analysis of their characteristics. Nucleic Acids Res 2008;36:37073715.

143 Yang J, Benyamin B, McEvoy BP, et al: Common SNPs explain a large proportion of the heritability for human height. Nat Genet 2010;42:565-569.

144 Yip RG, Boylan MO, Kieffer TJ, Wolfe MM: Functional GIP receptors are present on adipocytes. Endocrinology 1998;139:40044007

145 Yoganathan P, Karunakaran S, Ho MM, Clee SM: Nutritional regulation of genomewide association obesity genes in a tissuedependent manner. Nutr Metab (Lond) 2012;9:65.

46 Zhang H, Duan CJ, Chen W, et al: Clinical significance of SH2B1 adapter protein expression in non-small cell lung cancer. Asian Pac J Cancer Prev 2012;13:2355-2362. 


\section{Erratum}

In the article 'Functional Analysis of Seven Genes Linked to Body Mass Index and Adiposity by Genome-Wide Association Studies: A Review’ by Speakman (Hum Hered 2013;75:57-79) reference [123] to figure 10 was omitted. 